Research Article

\title{
Evaluation of Carbonisation Gas from Coal and Woody Biomass and Reduction Rate of Carbon Composite Pellets
}

\author{
Tateo Usui $\mathbb{D}^{1},{ }^{1}$ Hirokazu Konishi, ${ }^{2}$ Kazuhira Ichikawa, ${ }^{3}$ Hideki Ono, ${ }^{2}$ Hirotoshi Kawabata, \\ Francisco B. Pena, ${ }^{4,5}$ Matheus H. Souza, ${ }^{6}$ Alexandre A. Xavier, ${ }^{7}$ and Paulo S. Assis ${ }^{8}$ \\ ${ }^{1}$ Osaka University, 2-1 Yamadaoka, Suita, Osaka 565-0871, Japan \\ ${ }^{2}$ Graduate School of Engineering, Osaka University, 2-1 Yamadaoka, Suita, Osaka 565-0871, Japan \\ ${ }^{3}$ Osaka University, JFE Steel Corporation, 1 Kawasaki-cho, Chuo-ku, Chiba 260-0835, Japan \\ ${ }^{4}$ School of Mines, Federal University of Ouro Preto (UFOP), 35400-000 Ouro Preto, MG, Brazil \\ ${ }^{5}$ Vanzolini Foundation, University of São Paulo, Avenida Paulista, 967-3 ${ }^{\circ}$ Floor, 01311-100 São Paulo, SP, Brazil \\ ${ }^{6}$ School of Mines, UFOP, Campus Morro do Cruzeiro, 35400-000 Ouro Preto, MG, Brazil \\ ${ }^{7}$ School of Mines, UFOP, 522 Igaporã, 46490-000, BA, Brazil \\ ${ }^{8}$ Materials and Metallurgy, UFOP/REDEMAT, Praça Tiradentes 20, 35400-000 Ouro Preto, MG, Brazil
}

Correspondence should be addressed to Tateo Usui; usui@mat.eng.osaka-u.ac.jp

Received 26 June 2017; Accepted 28 September 2017; Published 11 March 2018

Academic Editor: Liming Lu

Copyright (c) 2018 Tateo Usui et al. This is an open access article distributed under the Creative Commons Attribution License, which permits unrestricted use, distribution, and reproduction in any medium, provided the original work is properly cited.

Carbon composite iron oxide pellets using semichar or semicharcoal were proposed from the measured results of the carbonisation gas release behaviour. The carbonisation was done under a rising temperature condition until arriving at a maximum carbonisation temperature $T_{c, \text { max }}$ to release some volatile matter $(\mathrm{VM})$. The starting point of reduction of carbon composite pellets using semicharcoal produced at $T_{c, \max }=823 \mathrm{~K}$ under the rising temperature condition was observed at the reduction temperature $T_{R}=833 \mathrm{~K}$, only a little higher than $T_{c, \text { max }}$, which was the aimed phenomenon for semicharcoal composite pellets. As $T_{c, \text { max }}$ increases, the emitted carbonisation gas volume increases, the residual VM decreases, and, as a whole, the total heat value of the carbonisation gas tends to increase monotonically. The effect of the particle size of the semicharcoal on the reduction rate was studied. When $T_{R}$ is higher than $T_{c, \max }$, the reduction rate increases, as the particle size decreases. When $T_{R}$ is equal to $T_{c, \max }$, there is no effect. With decreasing $T_{c, \max }$, the activation energy $E_{a}$ of semicharcoal decreases. The maximum carbonisation temperature $T_{c, \text { max }}$ may be optimised for reactivity $\left(1 / E_{a}\right)$ of semicharcoal and the total carbonisation gas volume or the heat value.

\section{Introduction}

The exhaustion of natural resources (quantity and quality) and $\mathrm{CO}_{2}$ emission controls are becoming increasingly important in steel industry. A lot of steel engineers studied various means to decrease reducing agents at blast furnace for reduction of $\mathrm{CO}_{2}$ emissions [1]. For example, injection of waste plastics [2] and carbon-neutral materials such as biomass into the blast furnace is a better alternative $[3,4]$. Especially, biomass has novel advantages, namely, no $\mathrm{CO}_{2}$ emissions because of carbon neutral. Production of carbon composite iron ore agglomerates having good reducibility and strength is becoming one of the most important subjects [5].
In previous work, effective use of coal especially the carbonisation gas was discussed in prereduction of iron oxide pellets for total smelting reduction process [6-8]. From these carbonisation data, it was proposed that novel carbon composite iron oxide pellets using semichar or semicharcoal and the residual volatile matter (VM) in char or charcoal could be used effectively. On this basis, data analyses of the carbonisation gases from coal and woody biomass have also been carried out to evaluate their chemical and thermal possibility.

\section{Background for the Present Work}

Prereduction experiments of iron oxide pellets for the total smelting reduction process were carried out with coal 
TABLE 1: Analyses of the samples used.

\begin{tabular}{|c|c|c|c|c|c|c|c|c|}
\hline \multicolumn{9}{|c|}{ mass\% } \\
\hline Sample & FC & $\mathrm{VM}$ & Ash & $S$ & $\mathrm{C}$ & $\mathrm{H}$ & $\mathrm{O}$ & $\mathrm{N}$ \\
\hline Newlands coal & 58.9 & 25.9 & 15.2 & 0.50 & 71.5 & 5.24 & 6.15 & 1.40 \\
\hline Newcastle blend coal & 58.7 & 32.8 & 8.5 & 0.54 & 74.8 & 4.90 & 9.27 & 1.97 \\
\hline Muswellbrook coal & 55.2 & 36.5 & 8.3 & 0.70 & 76.0 & 4.93 & 8.51 & 1.57 \\
\hline Japanese cedar & 12.05 & 87.38 & 0.57 & 0.01 & 52.52 & 6.76 & 40.4 & 0.03 \\
\hline Japanese cypress & 8.12 & 90.8 & 1.08 & 0.014 & 50.7 & 6.16 & 41.1 & 1.01 \\
\hline
\end{tabular}

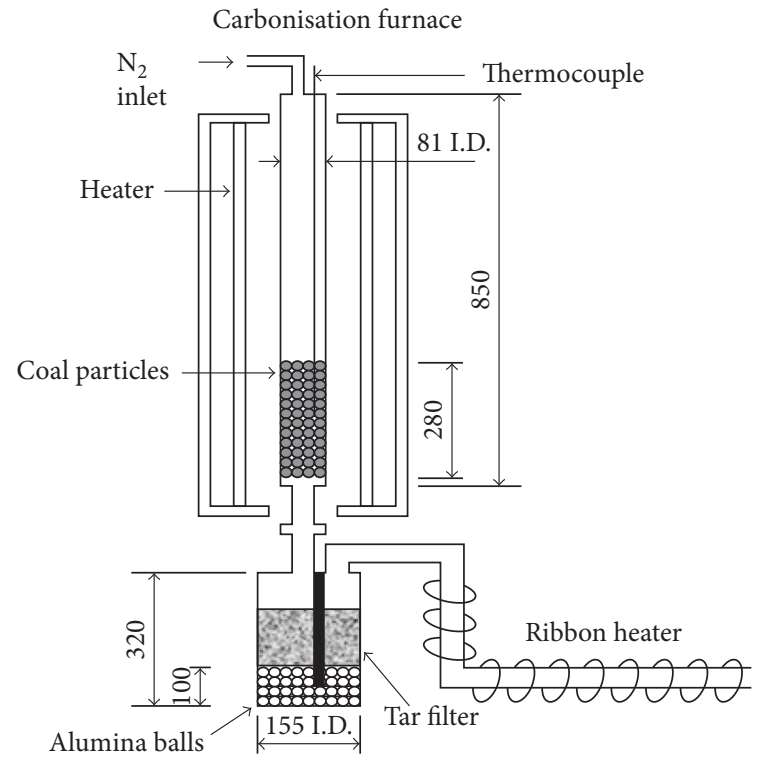

FIgURE 1: Schematic view of experimental apparatus for carbonisation of coal (or wood chips) (dimensions in $\mathrm{mm}$ ).

carbonisation gas [6-8]. In other words, coal carbonisation gases from various coals under different heating patterns were evaluated through the degree of prereduction at various reduction temperatures.

In the first step, three sorts of bituminous coal were carbonised under various rising temperature conditions (Table 1, Figures 1 and 2). In Table 1, samples (including two sorts of wood) are arranged in order of increasing volatile matter (VM). In Figure 1, schematic diagram of the experimental apparatus for carbonisation of the coal (or wood chips) is shown. Constant flow rate of $\mathrm{N}_{2}$ was added to determine the flow rates of carbonisation gas components as follows [7]: the volume ratios of carbonisation gas components and $\mathrm{N}_{2}$ were measured by a gas chromatograph, and then, the comparison of each gas component to $\mathrm{N}_{2}$ yielded the absolute flow rate of each gas component [7]. Subsequently, the carbonisation gas mixed with $\mathrm{N}_{2}$ gas flowed out from the exit of the reactor and was filtered and cooled to remove the tar and the water, respectively. After that, the gas without tar and water was analysed by gas chromatography (Figure 3). In Figure 2, typical heat patterns of carbonisation at a heating rate $r_{h}=200 \mathrm{~K} / \mathrm{h}$ are shown. After arriving at the maximum carbonisation temperature $T_{c, \max }$, the carbonisation

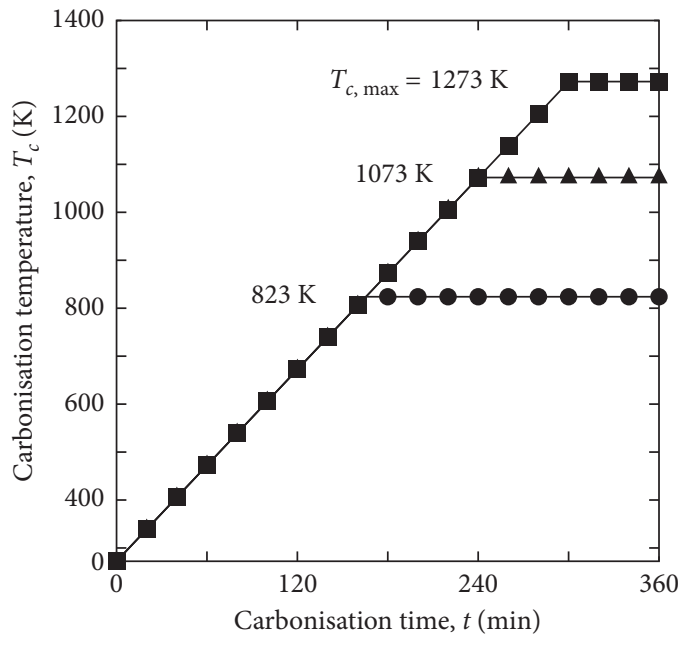

FIgURE 2: Typical heating patterns of coal carbonisation from room temperature to maximum carbonisation temperature $T_{c, \max }=823$, 1073 , and $1273 \mathrm{~K}$ at a heating rate of $200 \mathrm{~K} / \mathrm{h}$ and maintained at $T_{c, \text { max }}$ until total carbonisation time reached $360 \mathrm{~min}$.

temperature $T_{c}$ was maintained at $T_{c, \max }$ until total carbonisation time reached $360 \mathrm{~min}$.

Variation of each gas component with time was measured by gas chromatography (Figure 4 ). The reason to express the sum $\left(\mathrm{C}_{2} \mathrm{H}_{4}+\mathrm{C}_{2} \mathrm{H}_{6}+\mathrm{C}_{3} \mathrm{H}_{8}\right)$ for higher hydrocarbons is as follows: the present gas chromatograph could not divide the peaks of $\mathrm{C}_{2} \mathrm{H}_{4}$ and $\mathrm{C}_{2} \mathrm{H}_{6}$ and, moreover, the flow rates of $\mathrm{C}_{2} \mathrm{H}_{4}, \mathrm{C}_{2} \mathrm{H}_{6}$, and $\mathrm{C}_{3} \mathrm{H}_{8}$ were very small in comparison with the other gas components. In general, there was experimental error among each data set.

Figure 4 shows the total flow rate $V_{\text {Total }}$ (above) and mole fraction (below) of the carbonisation gas for Muswellbrook coal as a function of carbonisation time $t$. At $t=240 \mathrm{~min}$, the carbonisation temperature arrived at $T_{c, \text { max }}=1073 \mathrm{~K}$ and was maintained at $T_{c, \text { max }}$ until $360 \mathrm{~min}$ had elapsed. After $240 \mathrm{~min}$, the total flow rate decreased gradually. Around the carbonisation time of $0-120 \mathrm{~min}$ and 300-360 min, the total flow rate was relatively low; in these cases, the accuracy of the mole fraction would not be high. However, the overall picture of the gas composition can be seen easily. Hydrogen evolved at rather higher temperatures. Methane evolved from relatively lower carbonisation temperatures and continued across the temperature range. Higher hydrocarbons emitted within a lower temperature range. Both $\mathrm{CO}$ and $\mathrm{CO}_{2}$ evolved at 


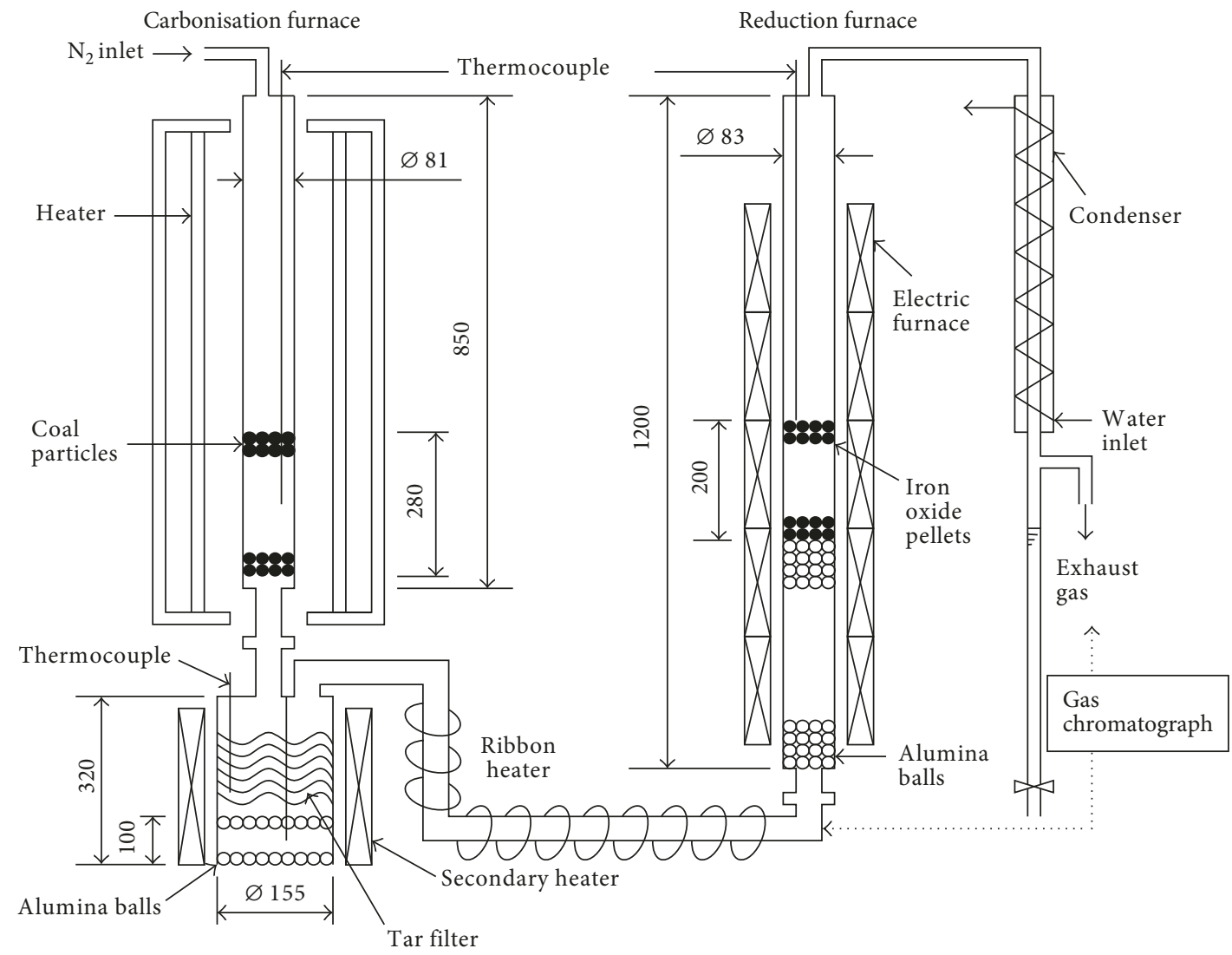

Figure 3: Schematic of the experimental apparatus for prereduction of iron oxide pellets by coal carbonisation gas (dimensions in mm).

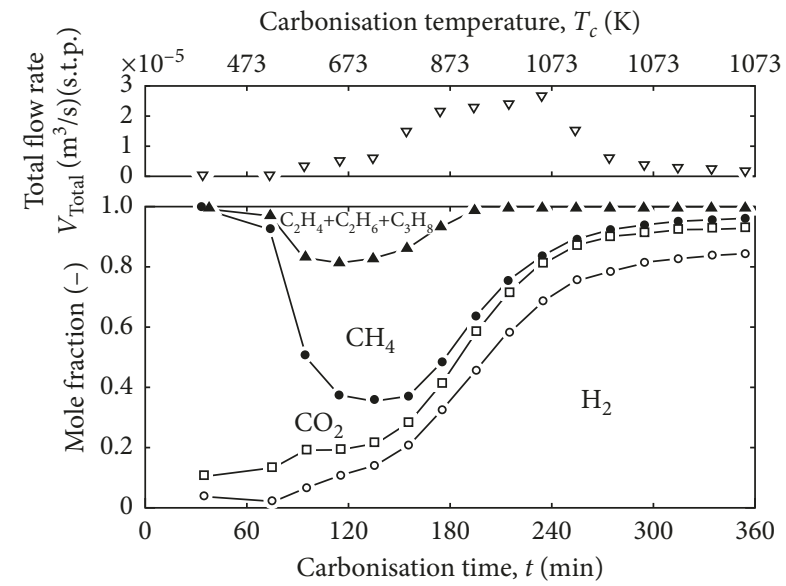

FIGURE 4: Mole fraction of carbonisation gas as a function of carbonisation time $t$ [6]. Carbonisation conditions: Muswellbrook coal: $1 \mathrm{~kg}$, carrier gas: $\mathrm{N}_{2} 1.0 \mathrm{~L} / \mathrm{min}$ (s.t.p.), maximum carbonisation temperature $\left(T_{c, \max }\right): 1073 \mathrm{~K}$, and heating rate $\left(r_{h}\right): 200 \mathrm{~K} / \mathrm{h}$; heating pattern is shown in Figure 2.

rather constant rates all over the carbonisation time. This fact introduced the concept of the use of semichar in a carbon composite pellet and will be discussed later (Figures 5 and 6).

In the second step, carbonisation gas was used to prereduce iron oxide pellets (Figures 3 and 7 ) for the iron bath smelting reduction process. The resultant char was

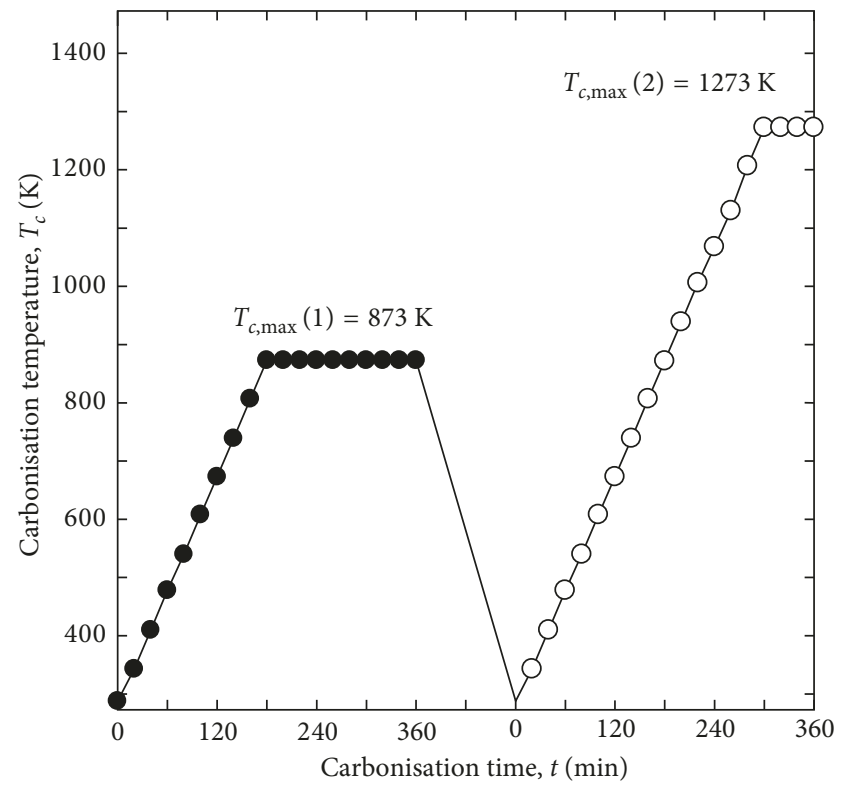

FIgURE 5: Two-step heat pattern of carbonisation (heating rate $\left.r_{h}=200 \mathrm{~K} / \mathrm{h}\right)$.

evaluated as a reducing agent and a heat source for iron bath by simulation (calculation only); optimum amount of coal in the total iron bath smelting reduction process including the proposed prereduction stage was estimated and compared with the amount of coking coal required 


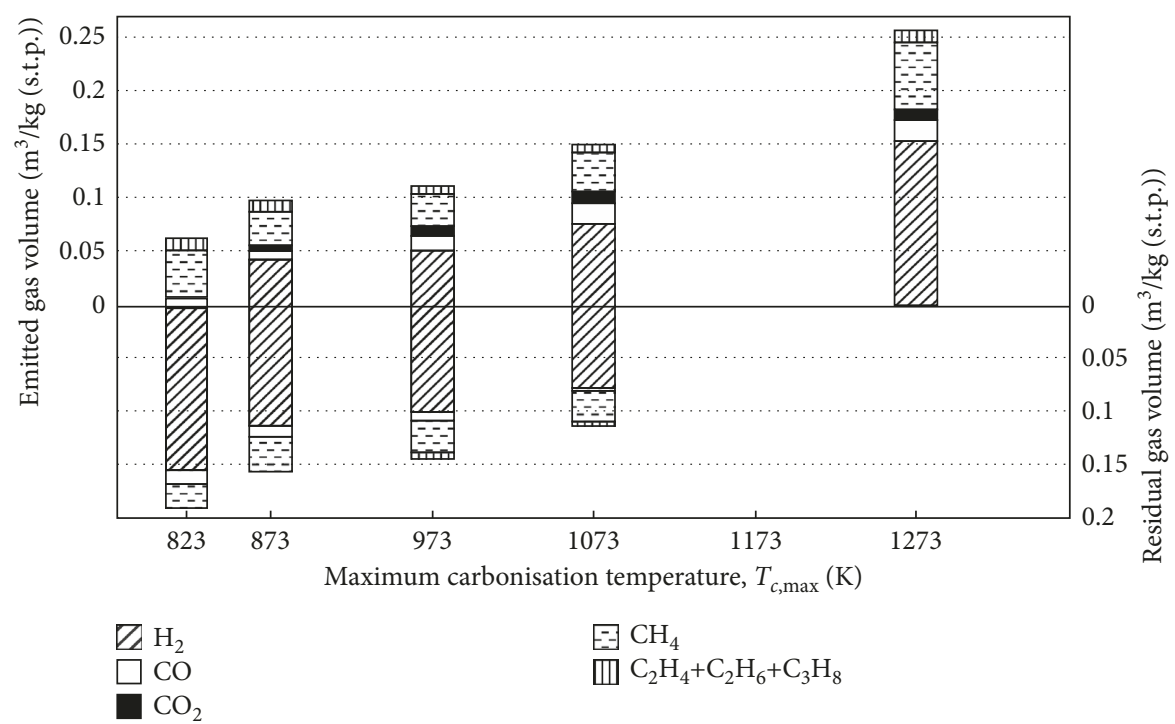

FIGURE 6: Emitted carbonisation gas volume and residual gas volume as a function of $T_{c, \max }$ (Newcastle blend coal, $r_{h}=200 \mathrm{~K} / \mathrm{h}$ ).

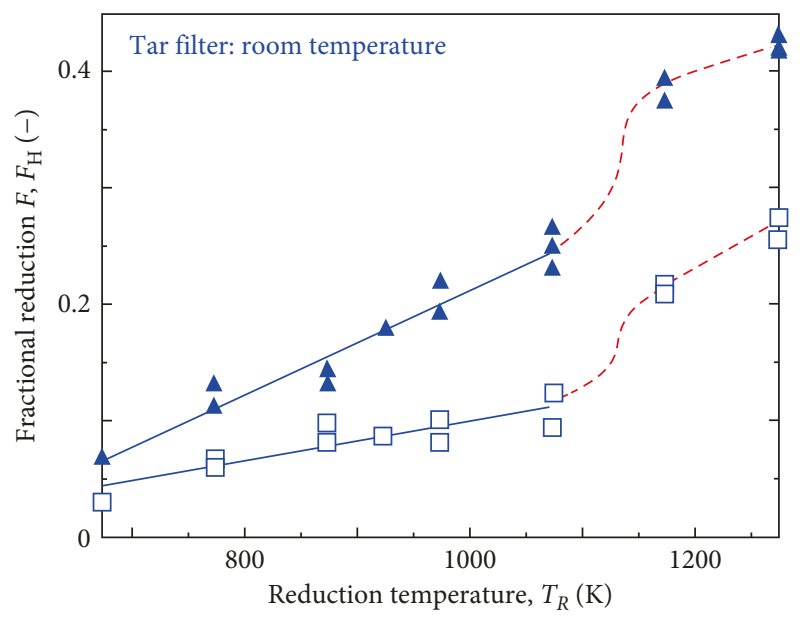

$\Delta$ Fractional reduction (gravimetric method)

$\square$ Fractional reduction due to $\mathrm{H}$

Figure 7: Variations of final fractional reductions $F$ and $F_{\mathrm{H}}$ with reduction temperature $T_{R}$ [7]. Experimental conditions: carbonisation of Muswellbrook coal $(1 \mathrm{~kg}), T_{c, \max }=1273 \mathrm{~K}, r_{h}=200 \mathrm{~K} / \mathrm{h}$ (Figure 2), carrier gas: $\mathrm{N}_{2} 1.0 \mathrm{~L} / \mathrm{min}$ (s.t.p.), secondary heater: off (Figure 3$)$, and reduction of Nibrasco pellets $(2 \mathrm{~kg})$.

for a conventional blast furnace route. The proposed route was shown to be marginally better than the conventional blast furnace route in terms of coal consumption rate [9].

Figure 3 shows schematic diagram of the experimental apparatus for the prereduction of iron oxide pellets by coal carbonisation gas. The carbonisation reactor is the same as shown in Figure 1. Fractional reduction was evaluated from the loss in weight of the packed pellets. Fractional reduction by $\mathrm{H}$ was also evaluated by the condensed water vapour. The secondary heater can be used for heating the tar to produce the secondary carbonisation gas.
Figure 7 shows the final fractional reduction calculated by the gravimetric method, $F$, and by the final fractional reduction due to $\mathrm{H}, F_{\mathrm{H}}$, as a function of reduction temperature $T_{R}$, where $\mathrm{H}$ originated in hydrogen gas and hydrocarbons and was measured as condensed water vapour from the exhaust gas after reduction. Both $F$ and $F_{\mathrm{H}}$ tend to increase linearly between $T_{R}=673 \mathrm{~K}$ and $1073 \mathrm{~K}$, and increase more than the extrapolated lines for $T_{R}>1073 \mathrm{~K}$, which suggests the contribution of hydrocarbons to reduction reaction at higher reduction temperatures, maybe by the catalytic effect of reducing iron oxides or reduced iron. The ratio of $F_{\mathrm{H}}$ to $F$ can be seen about 0.5 , which means very large contribution of $\mathrm{H}$ from hydrogen gas and hydrocarbons. The ultimate analysis is shown in Table 1 . In Table 1, the values are written in mass $\%$ and mass $\% \mathrm{H}$ is not so large, but mol\% is important in chemical reactions and 4.93 mass\% is large enough from this viewpoint.

\section{Experimental Procedure}

Carbon composite iron oxide pellets using semichar [10-12] were proposed from the measured results of the coal carbonisation gas release behaviour shown in the above section. Newlands coal, Newcastle blend coal, and Muswellbrook coal were used as samples of coal. Japanese cedar and Japanese cypress were used as samples of woody biomass. The analyses of the samples demonstrate that the woody biomass has much more VM and $\mathrm{O}$ and much less FC, ash, and $\mathrm{S}$ than the coals (Table 1). The carbonisation was done under a rising temperature condition at the same heating rate until arriving at the maximum carbonisation temperature $T_{c, \text { max }}$ in order to release some VM (Figure 2). The experiment was carried out by placing chips of the sample in the carbonisation reactor (Figure 1). Partly because some of the experimental items are the same as in Section 2 and partly because the present work covers many experimental items, the present experimental details are written in Section 4. 


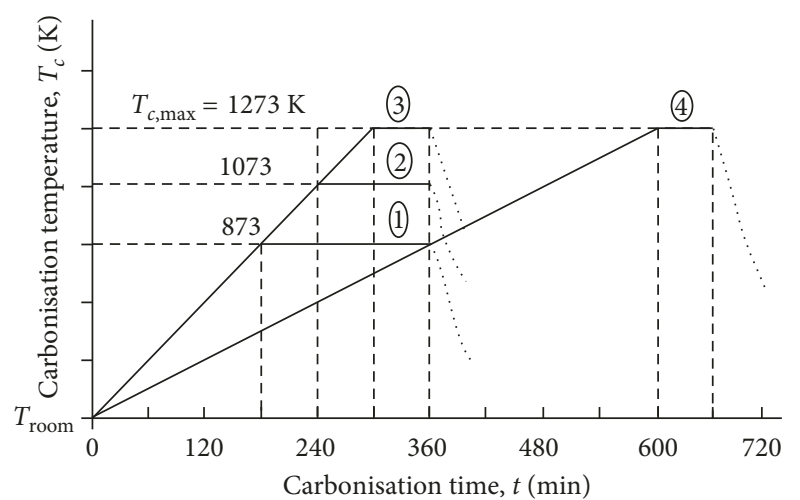

Figure 8: Heat patterns of carbonisation for Muswellbrook coal.

TABLE 2: Carbonisation gas from Muswellbrook coal.

\begin{tabular}{lcccc}
\hline \multicolumn{4}{c}{$\left[\mathrm{m}^{3} / \mathrm{kg}\right.$ (s.t.p.) $]$} & \\
Case (Figure 8) & 1 & 2 & 3 & 4 \\
\hline$r_{h}(\mathrm{~K} / \mathrm{h})$ & 200 & 200 & 200 & 100 \\
$T_{c, \text { max }}(\mathrm{K})$ & 873 & 1073 & 1273 & 1273 \\
$\mathrm{H}_{2}$ & 0.0326 & 0.0936 & 0.1252 & 0.1327 \\
$\mathrm{CO}$ & 0.0086 & 0.0212 & 0.0242 & 0.0232 \\
$\mathrm{CO}_{2}$ & 0.0084 & 0.0102 & 0.0112 & 0.0092 \\
$\mathrm{CH}_{4}$ & 0.0387 & 0.0515 & 0.0484 & 0.0516 \\
$\mathrm{C}_{2} \mathrm{H}_{4}+\mathrm{C}_{2} \mathrm{H}_{6}+\mathrm{C}_{3} \mathrm{H}_{8}$ & 0.0071 & 0.0071 & 0.0065 & 0.0066 \\
Total & 0.0955 & 0.1837 & 0.2155 & 0.2231 \\
\hline
\end{tabular}

\section{Results and Discussion}

4.1. Heating Rate of Carbonisation. In the case of Muswellbrook coal, two heating rates $\left(r_{h}\right), 100$ and $200 \mathrm{~K} / \mathrm{h}$, were used as shown in Figure 8; only carbonisation condition 4 (Case 4) was the lower heating rate of $100 \mathrm{~K} / \mathrm{h}$, applied to the Muswellbrook coal. This was applied to examine the effect of heating rate. When Case 4 in Figure 8 was applied, a little more total carbonisation gas was released, as shown in Table 2. However, the difference between total carbonisation gases of Cases 3 and 4 was only $3.4 \%$, and therefore, it is assumed that the sample obtained by Case 3 in Figure 8 released all the volatile matter. It is also assumed that the sample carbonised at $T_{c, \max }=1273 \mathrm{~K}$ under the heating rate of $200 \mathrm{~K} / \mathrm{h}$ released all the volatile matter for every coal sample.

\subsection{Carbon Composite Iron Oxide Pellets Using Semichar}

4.2.1. Two-Step Carbonisation Behaviour. It was inferred from the carbonisation experiments under rising temperature conditions (Figure 4) that when the carbonisation was interrupted, the volatile matter release would also be interrupted, and that when the carbonisation under rising temperature conditions was started again, the release of the residual volatile matter would begin at the same interrupted carbonising temperature. This inference was demonstrated by the following two-step carbonisation. Figure 5 shows the schematic heat pattern for two steps: the first

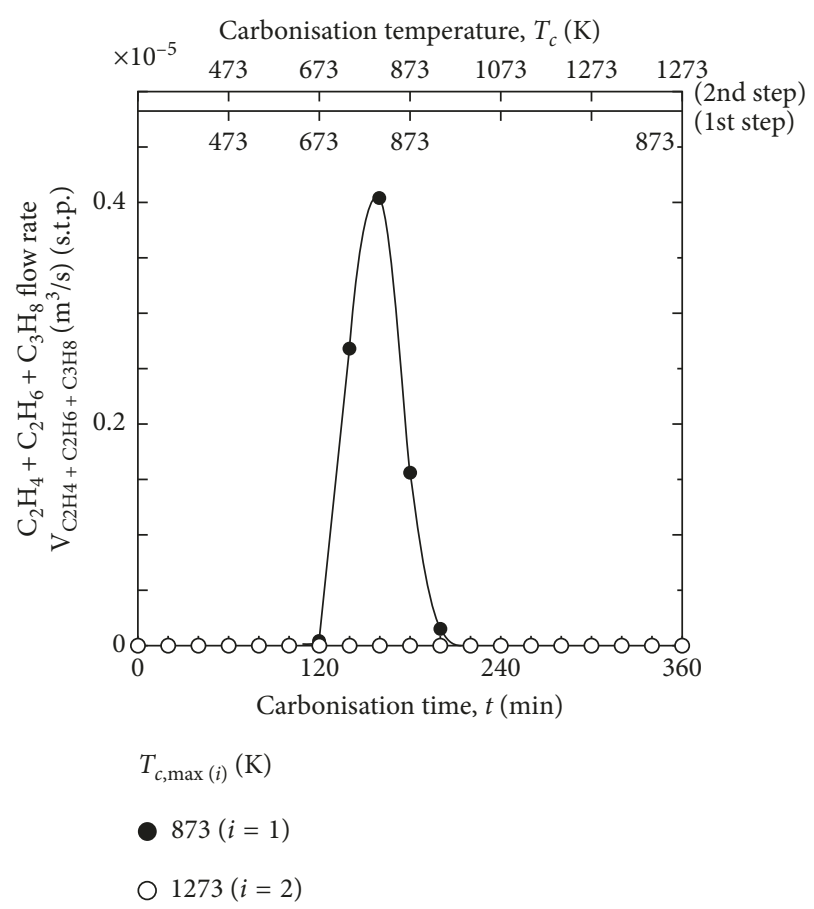

Figure 9: Variations of $\left(\mathrm{C}_{2} \mathrm{H}_{4}+\mathrm{C}_{2} \mathrm{H}_{6}+\mathrm{C}_{3} \mathrm{H}_{8}\right)$ flow rate with carbonisation time in the two-step carbonisation [10].

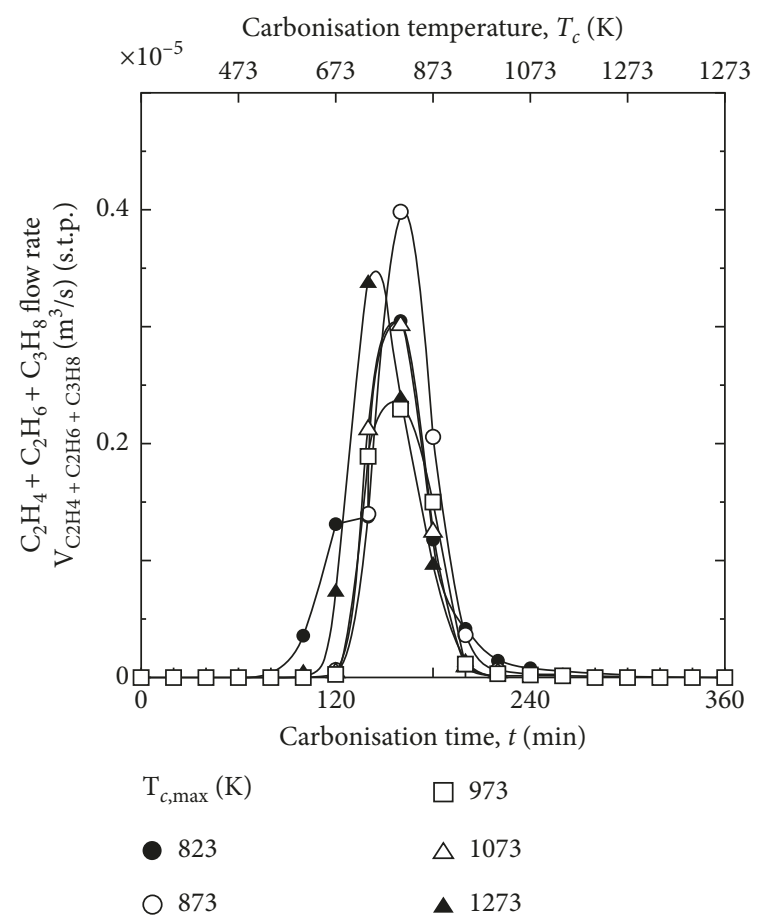

Figure 10: Variations of $\left(\mathrm{C}_{2} \mathrm{H}_{4}+\mathrm{C}_{2} \mathrm{H}_{6}+\mathrm{C}_{3} \mathrm{H}_{8}\right)$ flow rate with carbonisation time in the one-step carbonisation [10].

carbonisation at $T_{c, \text { max }}(1)=873 \mathrm{~K}$ and the second one at $T_{c}$, $\max (2)=1273 \mathrm{~K}$.

Figures 9 through 13 in [10] show flow rates of the emitted gas components $\mathrm{H}_{2}, \mathrm{CO}, \mathrm{CO}_{2}, \mathrm{CH}_{4}$, and $\left(\mathrm{C}_{2} \mathrm{H}_{4}+\mathrm{C}_{2} \mathrm{H}_{6}+\mathrm{C}_{3} \mathrm{H}_{8}\right)$ by two-step carbonisation of Newcastle blend coal at each 
maximum carbonisation temperature $T_{c, \max }$ under the heating rate $r_{h}=200 \mathrm{~K} / \mathrm{h}$. After the first carbonisation at $T_{c, \text { max }}(1)=$ $873 \mathrm{~K}$, when the carbonisation was started again (the second carbonisation at $T_{c, \text { max }}(2)=1273 \mathrm{~K}$ ), the release of the residual volatile matter began at almost the same interrupted carbonising temperature $T_{c}=873 \mathrm{~K}$. In Figure 9, cited from Figure 13 of [10], the total flow rate of $\left(\mathrm{C}_{2} \mathrm{H}_{4}+\mathrm{C}_{2} \mathrm{H}_{6}+\mathrm{C}_{3} \mathrm{H}_{8}\right)$ is negligibly small all over $(t=0-360 \mathrm{~min})$ for the second carbonisation at $T_{c, \max }(2)=1273 \mathrm{~K}$, which can be easily understood from Figure 10, cited from Figure 7 of [10]; almost all the higher hydrocarbons $\left(\mathrm{C}_{2} \mathrm{H}_{4}+\mathrm{C}_{2} \mathrm{H}_{6}+\mathrm{C}_{3} \mathrm{H}_{8}\right)$ are released at $T_{c}=873 \mathrm{~K}$.

Moreover, from Figure 14 of [10], the total and individual carbonisation gas volumes for one-step $\left(T_{c, \text { max }}=1273 \mathrm{~K}\right)$ and two-step $\left(T_{c \text {, max }}(1)=873 \mathrm{~K}\right.$ and $\left.T_{c, \text { max }}(2)=1273 \mathrm{~K}\right)$ carbonisation were almost the same.

From these findings, novel carbon composite pellets were proposed, in which the semichar including the residual volatile matter was used as the carbonaceous material. When fully carbonised char is used as the carbonaceous material, the reduction of carbon composite pellets initially occurs as a solid/solid reaction under rising temperature conditions as in a blast furnace.

Whereas, when semichar is used as the carbonaceous material, the reduction of carbon composite pellets starts earlier as a gas/solid reaction just after the reduction temperature $T_{R}$ arrives at $T_{c, \text { max}}$. In general, in the case of the semichar produced at lower maximum carbonisation temperature, $T_{c, \max }$, the carbon composite pellets started the reduction reaction at the reduction temperature only a little higher than $T_{c \text {,max }}$ under a rising temperature condition (see Figure 11 for semicharcoal composite pellets). The starting temperature of reduction and the quantity of residual volatile matter (VM) can be changed simultaneously (but not independently) by controlling $T_{c, \max }$. Coal type could also be selected on the basis of VM content.

Therefore, the first benefit is the decrease in the starting temperature of reaction, and the second one is the improved rate of reduction reaction by the residual volatile matter. The decrease in the starting temperature of reduction reaction of iron ore in a blast furnace leads to the decrease in consumption of reducing agents and hence, a productivity improvement.

4.2.2. Reduction Behaviour of Carbon Composite Iron Oxide Pellets Using Semichar. Preparation of carbon composite iron oxide pellets was as follows:

Mass ratio semichar: $\mathrm{Fe}_{2} \mathrm{O}_{3}=1: 4$.

Particle size: less than $63 \mu \mathrm{m}$.

Binder: bentonite (1 mass\% added).

Pellet size: about $15 \mathrm{~mm}$.

Drying at $378 \mathrm{~K}$ for $24 \mathrm{~h}$ to remove water.

Reagent grade hematite (95 mass $\% \mathrm{Fe}_{2} \mathrm{O}_{3}$, particle size: less than $44 \mu \mathrm{m}$ ) was used for iron oxide. The chemical analysis of the bentonite is shown in Table 3, from which almost no effect of the bentonite is expected upon the reduction reaction because $\mathrm{Fe}_{2} \mathrm{O}_{3}$ content is as low as 3 mass\% and the addition of the bentonite is 1 mass $\%$. The semichar used was produced from Newcastle blend coal (Table 1).

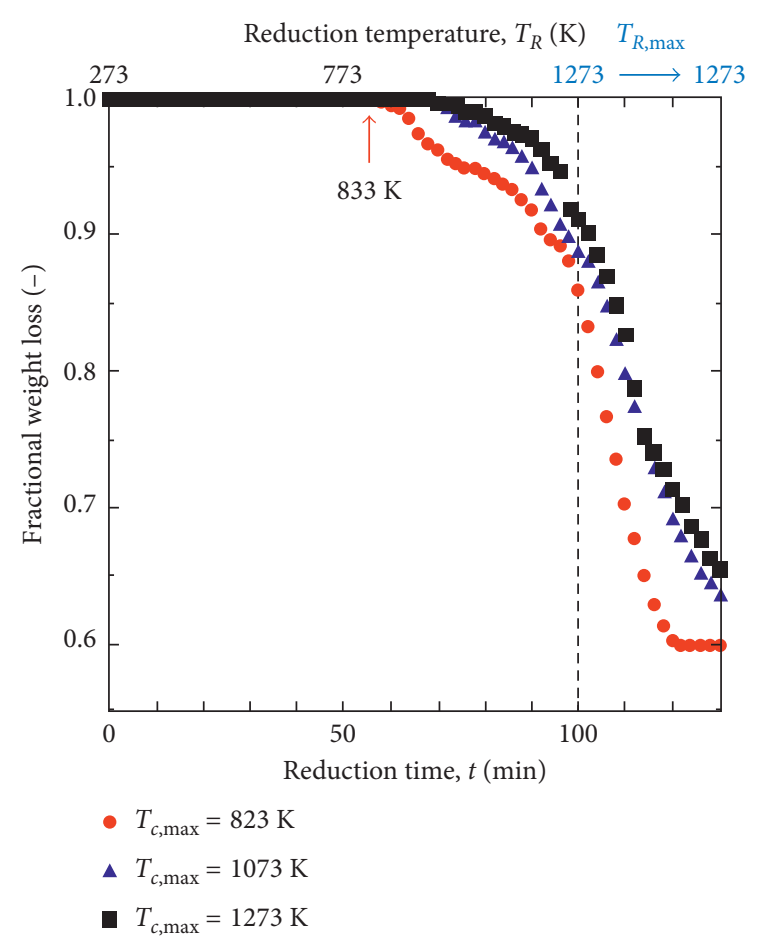

FIgURE 11: Weight loss curves in $\mathrm{N}_{2}$ gas atmosphere for carbon composite pellets using semicharcoal produced at $T_{c, \max }=823$, 1073 , and $1273 \mathrm{~K}\left(r_{h}=200 \mathrm{~K} / \mathrm{h}\right)$ from Japanese cypress under the rising temperature condition at $10 \mathrm{~K} / \mathrm{min}$. Particle size range for the semicharcoal is $63-75 \mu \mathrm{m}$.

TABLe 3: Chemical analysis of the bentonite used.

\begin{tabular}{lcccccc}
\hline & \multicolumn{7}{c}{ mass\% } \\
$\mathrm{SiO}_{2}$ & $\mathrm{Al}_{2} \mathrm{O}_{3}$ & $\mathrm{Fe}_{2} \mathrm{O}_{3}$ & $\mathrm{CaO}$ & $\mathrm{MgO}$ & $\mathrm{K}_{2} \mathrm{O}$ & $\mathrm{Na}_{2} \mathrm{O}$ \\
\hline 58.79 & 14.27 & 2.99 & 0.70 & 1.28 & 0.70 & 3.42 \\
\hline
\end{tabular}

TABle 4: Analyses of semichar carbonised from Newcastle blend coal at $T_{c, \max }=823,1073$, and $1273 \mathrm{~K}\left(r_{h}=200 \mathrm{~K} / \mathrm{h}\right)$.

\begin{tabular}{lcccccccc}
\hline & \multicolumn{8}{c}{ mass\% } \\
$T_{c, \text { max }}(\mathrm{K})$ & $\mathrm{FC}$ & $\mathrm{VM}$ & Ash & $\mathrm{S}$ & $\mathrm{C}$ & $\mathrm{H}$ & $\mathrm{O}$ & $\mathrm{N}$ \\
\hline Initial & 58.7 & 32.8 & 8.5 & 0.54 & 74.8 & 4.90 & 9.27 & 1.97 \\
823 & 72.17 & 15.93 & 11.90 & 0.53 & 75.33 & 2.87 & 7.31 & 2.06 \\
1073 & 82.70 & 4.43 & 12.87 & 0.42 & 81.52 & 1.54 & 1.91 & 1.74 \\
1273 & 83.21 & 2.51 & 12.28 & 0.52 & 81.69 & 0.90 & 1.34 & 1.27 \\
\hline
\end{tabular}

Newcastle blend coal was carbonised from room temperature to $T_{c, \text { max }}=823,873,973,1073$, or $1273 \mathrm{~K}$ at a heating rate of $200 \mathrm{~K} / \mathrm{h}$ under the same heating time of $360 \mathrm{~min}$, as shown in Figure 2. The obtained semichar was mixed with reagent grade hematite along with bentonite as a binder in order to strengthen. The semichar composite pellet was prepared by hand rolling.

Emitted and residual carbonisation gas volumes as a function of $T_{c, \max }$ are shown in Figure 6. As $T_{c, \max }$ increases, 


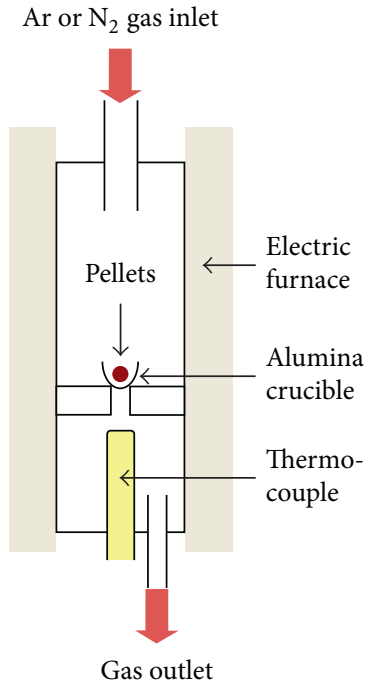

Figure 12: Experimental apparatus for reduction of carbon composite pellets.

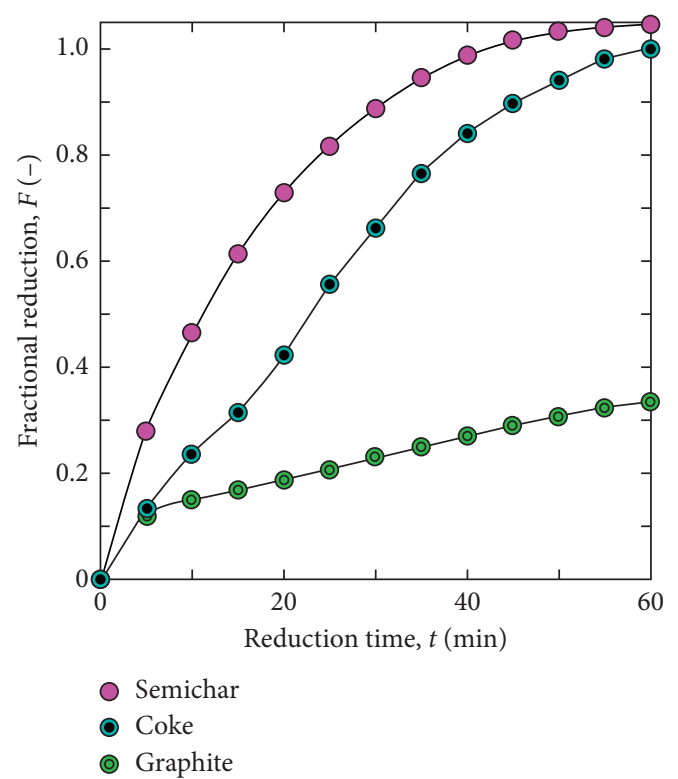

FIGURE 13: Comparison of reduction curves for carbon composite pellets using semichar, coke, and graphite $\left(T_{R}=1273 \mathrm{~K}\right)$.

emitted gas volumes of $\mathrm{H}_{2}$ and $\mathrm{CO}$ increase and consequently residual gas volumes of $\mathrm{H}_{2}$ and $\mathrm{CO}$ decrease. The residual gas volume was calculated under the assumption that all the carbonisation gas components were emitted at $T_{c, \max }=1273 \mathrm{~K}$, as mentioned previously.

Table 4 shows the analyses of semichar carbonised from Newcastle blend coal at $T_{c, \max }=823,1073$, and $1273 \mathrm{~K}$. As $T_{c, \text { max }}$ increases, the residual volatile matter (VM) decreases clearly in Proximate analysis and $\mathrm{H}$ and $\mathrm{O}$ decrease gradually in Ultimate analysis, while FC in Proximate analysis and C in Ultimate analysis increase gradually.

Figure 12 shows schematic view of experimental apparatus for reduction of carbon composite iron oxide pellets in Ar or $\mathrm{N}_{2}$ gas atmosphere. Constant flow rate of $\mathrm{N}_{2}$ was added to determine the flow rates of exhaust gas components [7]; the generated gases of $\mathrm{H}_{2}, \mathrm{CO}, \mathrm{CO}_{2}, \mathrm{CH}_{4},\left(\mathrm{C}_{2} \mathrm{H}_{4}+\mathrm{C}_{2} \mathrm{H}_{6}+\mathrm{C}_{3} \mathrm{H}_{8}\right)$, and $\mathrm{H}_{2} \mathrm{O}$ along with $\mathrm{N}_{2}$ were analysed by the gas chromatography and the quadrupole mass spectrometry. Fractional reduction $F(-)$ was calculated by

$$
F=\frac{\left(\mathrm{M}_{\mathrm{O} \text { in reaction gas }}-\mathrm{M}_{\mathrm{O} \text { in volatile matter }}\right)}{\mathrm{R}_{\mathrm{O}}},
$$

where $\mathrm{M}_{\mathrm{O}}$ in reaction gas is the total mole of oxygen in generated gases on iron oxide reduction (mol), $\mathrm{M}_{\mathrm{O}}$ in volatile matter is the total mole of oxygen in the released gas on carbonisation of carbonaceous materials $(\mathrm{mol})$, and $\mathrm{R}_{\mathrm{O}}$ is the total mole of oxygen in case of reducing $\mathrm{Fe}_{2} \mathrm{O}_{3}$ as an iron oxide sample perfectly (mol) [13].

Figure 13 shows the comparison of reduction curves (fractional reduction $F$ versus reduction time $t$ ) at reduction temperature $T_{R}=1273 \mathrm{~K}$ in $\mathrm{N}_{2}$ gas atmosphere for carbon composite iron oxide pellets using semichar from Newcastle blend coal $\left(T_{c, \max }=823 \mathrm{~K}\right.$ and $\left.r_{h}=200 \mathrm{~K} / \mathrm{h}\right)$, coke $(\mathrm{VM}=0.6$ mass\%), and graphite (purity 98\%). Particle size ranges for the semichar and coke are less than $63 \mu \mathrm{m}$ and for the graphite less than $43 \mu \mathrm{m}$. The effect of the residual volatile matter in the semichar reductant can be easily seen with reduction occurring earlier and at a faster rate. The reduction rate of the graphite is much less than that of the coke, which can be explained by the degree of crystallization; the degree of crystallization of the graphite is higher than that of the coke (for another example, see Figure 14, which shows that the semichar has a crystalline structure but semicharcoal shows amorphous nature. In general, when the degree of crystallization is lower, the gasification rate is higher, and therefore, the reduction of carbon composite pellets using semicharcoal proceeds faster than that using semichar).

4.3. Carbon Composite Iron Oxide Pellets Using Semicharcoal. Semicharcoal [13-15] was also used to produce carbon composite pellets. The use of semicharcoal is aimed at not only because of carbon-neutral material but also because of high reactivity (reactivity $=1 / E_{a}$, Table 5 ).

4.3.1. Carbonisation Gases from Woods in Comparison with Those from Coals. Figure 15 depicts total and individual components of carbonisation gases for Japanese cypress $(200 \mathrm{~g})$ as a function of the maximum carbonisation temperature $T_{c, \max }$, where the heating patterns are the same as in Figure 2. As $T_{c, \max }$ increases, $\mathrm{H}_{2}$ emission increases significantly, but the other components are relatively stable across the temperature range. The ratios of $\mathrm{CO}$ and $\mathrm{CO}_{2}$ are large, and those volumes are much the same with each other.

Table 6 shows the analyses of semicharcoal carbonised from Japanese cypress at $T_{c, \max }=823,1073$, and $1273 \mathrm{~K}$ with coke included for comparison. As $T_{c, \max }$ increases, the residual volatile matter (VM) decreases clearly in Proximate analysis and $\mathrm{H}$ and $\mathrm{O}$ also decrease clearly in Ultimate analysis, while FC and C increase gradually. The residual volatile matter value in the semicharcoal carbonised from Japanese cypress at $T_{c, \max }=1273 \mathrm{~K}$ is relatively large and 


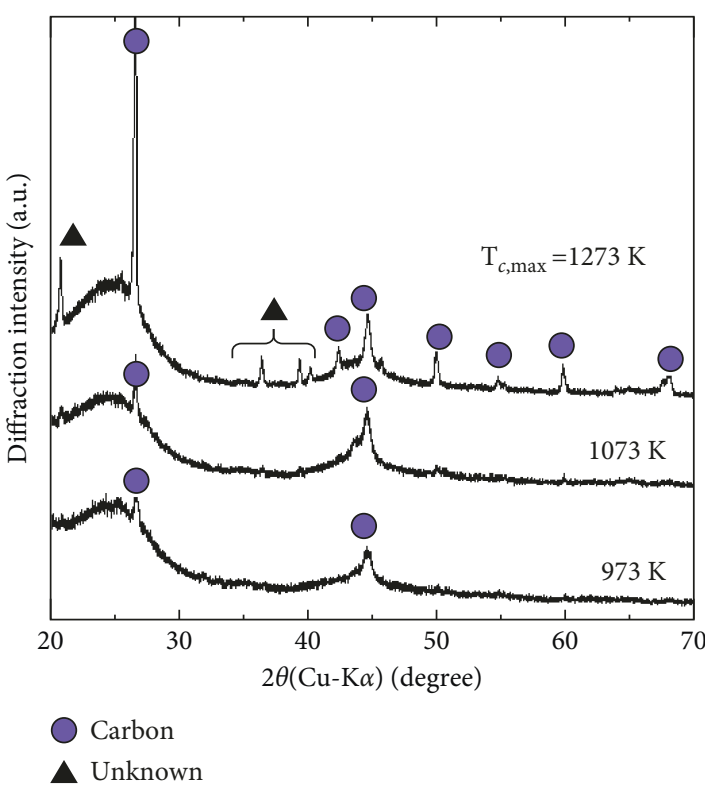

(a)

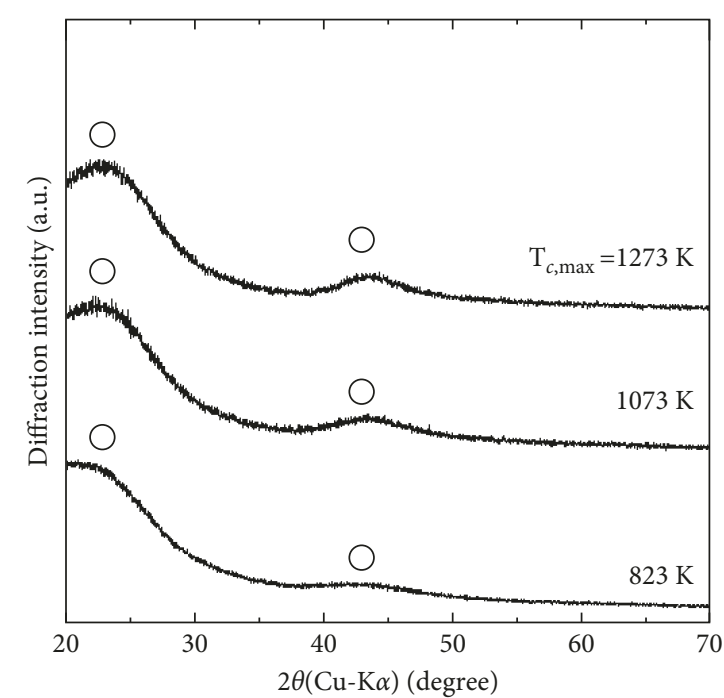

Carbon

(b)

FIGURE 14: Comparison between the crystal structures of semichar (Newcastle blend coal) and semicharcoal (Japanese cypress) by XRD measurements. (a) Semichar. (b) Semicharcoal.

TABLE 5: Comparison of activation energies for various carbonaceous materials.

\begin{tabular}{lc}
\hline Carbonaceous material & Activation energy $E_{a}(\mathrm{~kJ} / \mathrm{mol})$ \\
\hline Graphite & $217[16]$ \\
Bintyo char & $182[16]$ \\
Bamboo char & $181[16]$ \\
Coke & $200[16]$ \\
Glassy carbon & $211[16]$ \\
Activated carbon & $149[16]$ \\
Semicharcoal at $T_{c, \max }=823 \mathrm{~K}$ & $138^{*}$ \\
Semicharcoal at $T_{c, \max }=1073 \mathrm{~K}$ & $139^{*}$ \\
Semicharcoal at $T_{c, \max }=1273 \mathrm{~K}$ & $162^{*}$ \\
Semichar at $T_{c, \max }=1073 \mathrm{~K}$ & $174^{*}$ \\
Coke & $219^{*}$ \\
\hline
\end{tabular}

${ }^{*}$ Present work (by gasification experiments), where the semicharcoal was obtained from Japanese cypress and semichar from Newcastle blend coal (Table 1), and the analyses of the coke are shown in Table 6 .

much larger than the one in the semichar carbonised from Newcastle blend coal at $T_{c, \max }=1273 \mathrm{~K}$ (Table 4).

Figure 16 shows surface views of Japanese cypress carbonised at $T_{c, \max }=823$ and $1273 \mathrm{~K}$ by using an optical microscope. Semicharcoal has many micropores with the size of about $10 \mu \mathrm{m}$.

Figure 17 illustrates comparisons of carbonisation gas volumes for all the analysed samples at $T_{c, \max }=1073$ and $1273 \mathrm{~K}$ and $r_{h}=200 \mathrm{~K} / \mathrm{h}$. From Figure 17, it can be seen that coal and wood release almost similar total quantities of carbonisation gas. The first important point is the clear difference between the kinds of carbonisation gas components released from coals and woods. The second important point is large quantities of $\mathrm{H}_{2}$

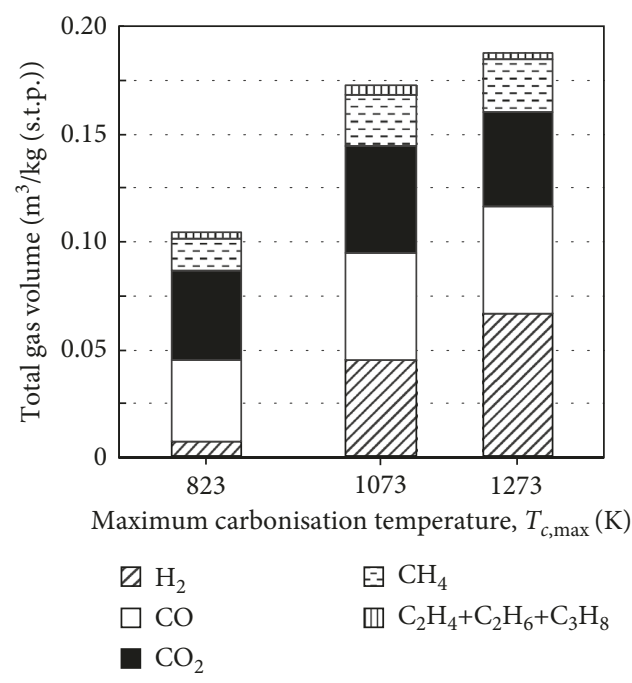

FIGURE 15: Total and individual components of carbonisation gases for Japanese cypress as a function of $T_{c, \max }\left(r_{h}=200 \mathrm{~K} / \mathrm{h}\right)$.

and $\mathrm{CH}_{4}$ released from the samples of coal. This can be explained by the structure of the coal, which is composed of mainly carbon and hydrogen. The third important point is that wood releases great amount of $\mathrm{CO}$ and $\mathrm{CO}_{2}$ because of the large quantity of oxygen in its structure (Table 1). From Figure 6 , it can be seen that the carbonisation gas will stay more within coal (or wood) especially in the residual VM, as the maximum carbonisation temperature decreases. Naturally, the total volume of carbonisation gas released at $T_{c, \max }=1273 \mathrm{~K}$ is always higher than the one at $T_{c, \max }=1073 \mathrm{~K}$ for all the samples used, which leads to results of the total amount of heat discussed later (Figure 18). 
TABLE 6: Analyses of semicharcoal carbonised from Japanese cypress at $T_{c, \max }=823,1073$, and $1273 \mathrm{~K}\left(r_{h}=200 \mathrm{~K} / \mathrm{h}\right)$ in comparison with coke.

\begin{tabular}{lccccccccc}
\hline & & \multicolumn{3}{c}{ mass $\%$} & & & & \\
& $T_{c, \max }(\mathrm{K})$ & $\mathrm{FC}$ & $\mathrm{VM}$ & $\mathrm{Ash}$ & $\mathrm{S}$ & $\mathrm{C}$ & $\mathrm{O}$ & $\mathrm{N}$ \\
\hline Japanese cypress & - & 8.12 & 90.8 & 1.08 & 0.014 & 50.7 & 6.16 & 41.1 \\
& 823 & 80.60 & 18.65 & 0.76 & 0.01 & 85.8 & 2.93 & 9.89 & 0.60 \\
Semicharcoal & 1073 & 89.35 & 9.64 & 1.01 & 0.03 & 91.2 & 1.33 & 5.89 & 0.55 \\
& 1273 & 91.80 & 7.00 & 1.16 & 0.04 & 92.6 & 0.56 & 4.81 & 0.82 \\
Coke & - & 87.1 & 0.97 & 11.97 & 0.60 & 84.6 & 0.26 & 1.35 & 1.22 \\
\hline
\end{tabular}

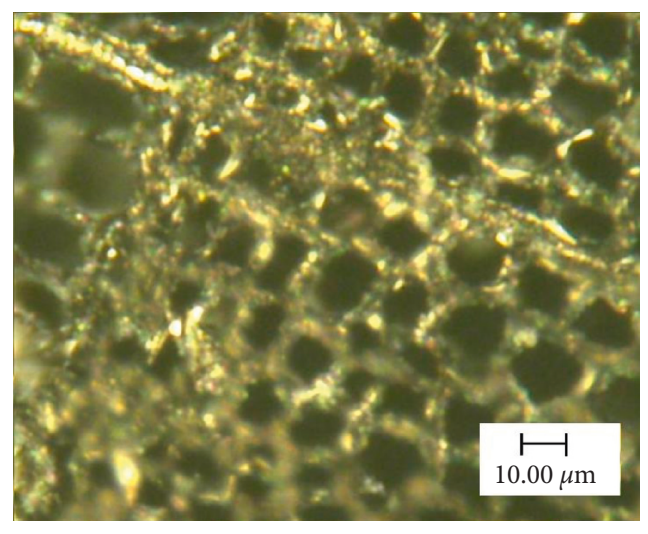

(a)

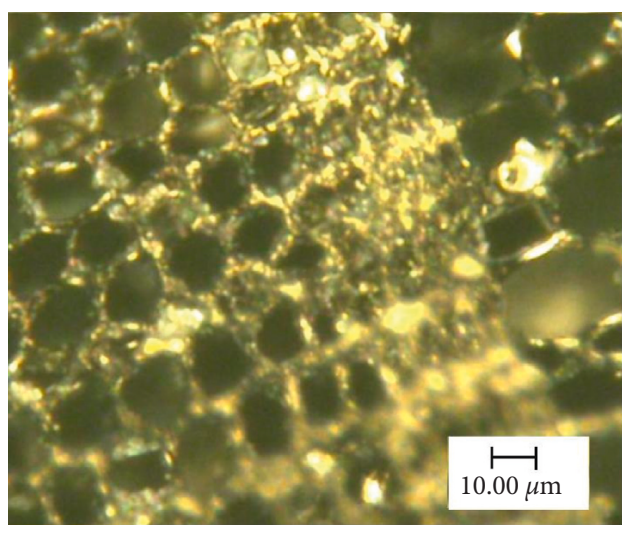

(b)

Figure 16: Surface views of Japanese cypress carbonised at $T_{c, \max }=823$ and $1273 \mathrm{~K}\left(r_{h}=200 \mathrm{~K} / \mathrm{h}\right)$; photos were taken by an optical microscope. (a) $T_{c, \max }=823 \mathrm{~K}$. (b) $T_{c, \max }=1273 \mathrm{~K}$.

Figure 19 summarizes total carbonisation gas volumes as a function of $T_{c, \text { max }}$. On the whole, total carbonisation gas volumes for all the samples used increase monotonically with $T_{c, \text { max }}$.

\subsubsection{Starting Point of Reduction of Semicharcoal Composite} Pellet under Rising Temperature. Figure 20 shows schematic view of experimental apparatus for measuring weight loss of a sample by a gravimetric method; in the upper box, a strain gauge-type transducer was equipped to measure the weight loss of the sample. The balance was used to counter the initial weight to be zero. Inside of the box was cooled by an $\mathrm{N}_{2}$ flow to keep the transducer at a constant temperature.

Figure 11 shows weight loss curves in $\mathrm{N}_{2}$ gas atmosphere for carbon composite iron oxide pellets using semicharcoal produced at $T_{c, \text { max }}=823,1073$, and $1273 \mathrm{~K}$ from Japanese cypress under the rising temperature condition at $10 \mathrm{~K} / \mathrm{min}$ (reduction temperature $T_{R}$ from room temperature till the maximum temperature $T_{R, \text { max }}=1273 \mathrm{~K}$ ). At $T_{c, \text { max }}=823 \mathrm{~K}$, the weight loss started at $T_{R}=833 \mathrm{~K}$, which is only slightly higher than $T_{c, \max }$.

4.3.3. Effect of Particle Size of Semicharcoal upon the Reduction Rate. In order to clarify the effect of particle size of semicharcoal upon the reduction rate of the composite pellets, variations of reduction curves at the reduction temperature $T_{R}=1073$ and $1273 \mathrm{~K}$ in $\mathrm{N}_{2}$ gas atmosphere for carbon composite iron oxide pellets using semicharcoal produced at $T_{c, \text { max }}=1073 \mathrm{~K}$ from Japanese cypress with the particle size are depicted in Figure 21.

In this experiment, the apparatus used is the same as shown in Figure 12 and fractional reduction $F$ was calculated by (1).

By using sieves, the particle size ranges were divided into the following three: $23-35,63-75$, and $105-150 \mu \mathrm{m}$. In the case of Figure 21 (a) at $T_{R}=1073 \mathrm{~K}$, the particle size dependence cannot be distinguished. In this case, the residual VM is unable to be released because $T_{R}=T_{c \text {, max }}$. On the other hand, in the case of Figure $21(\mathrm{~b})$ at $T_{R}=1273 \mathrm{~K}$, the residual VM is able to be released because $T_{R}>T_{c \text {, max }}$, and moreover, the effect of particle size is very clear; the reduction rate of the composite pellet increases, as the particle size decreases, as a consequence of the specific surface area increasing.

4.3.4. Comparison between Semichar and Semicharcoal. The rate enhancement effect of reduction for semicharcoal composite pellets is stronger than that for semichar composite pellets [15] because the gasification rate of semicharcoal is higher than that of semichar (Figures 22 and 23). This is caused by the following reasons: semicharcoal has an amorphous nature, while semichar has a more crystalline structure (Figure 14), and the activation energy of semicharcoal is lower than that of semichar (Table 5).

Figure 14 in [15] shows the comparison between the reduction curves of carbon composite pellets using 


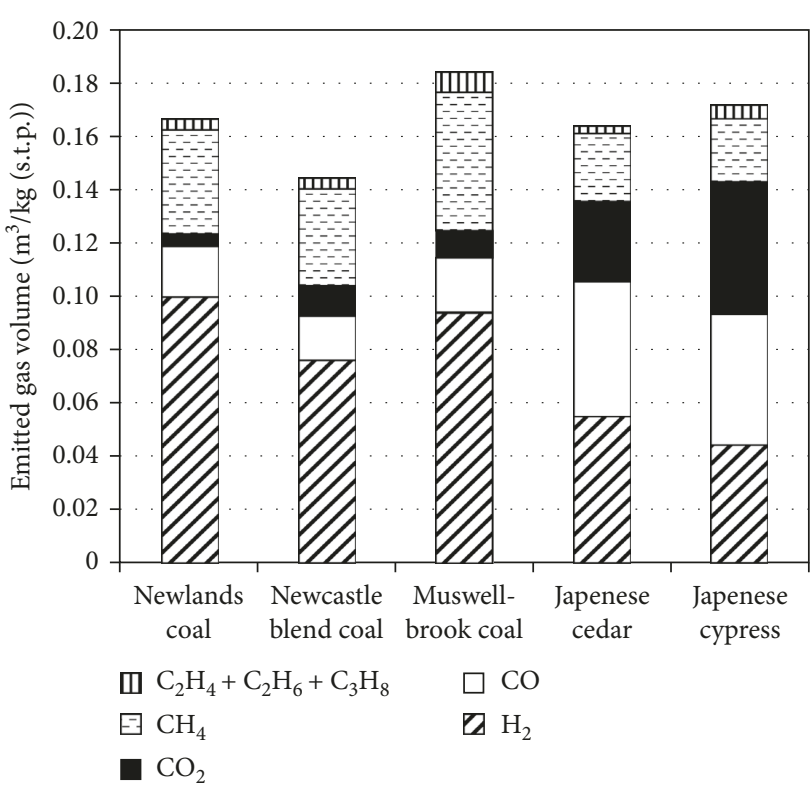

(a)

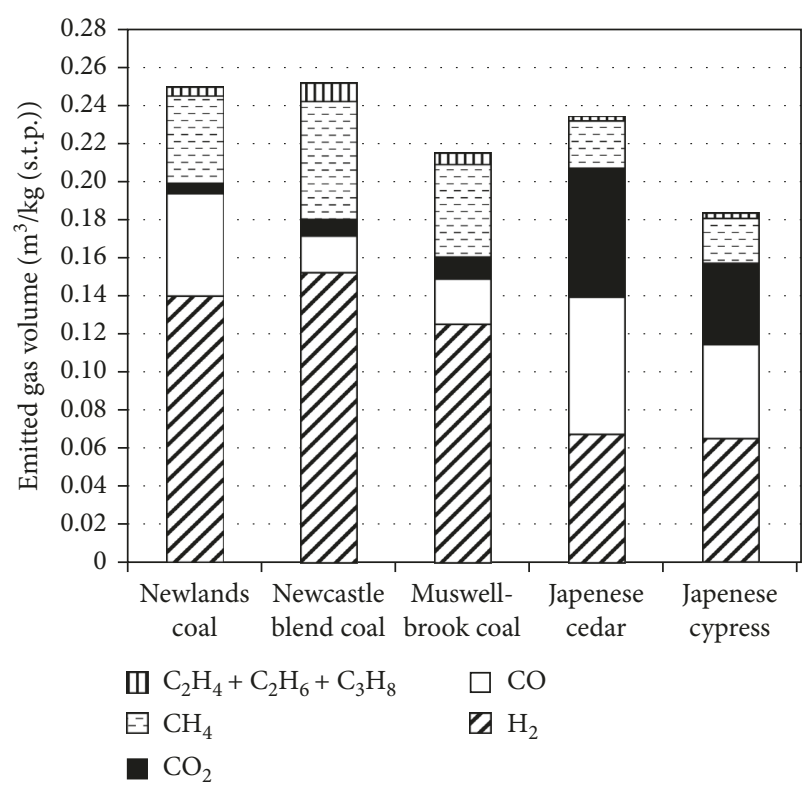

(b)

FIgURE 17: Carbonisation gas volumes at $T_{c, \max }=1073$ and $1273 \mathrm{~K}$ and $r_{h}=200 \mathrm{~K} / \mathrm{h}$. (a) $T_{c, \max }=1073 \mathrm{~K}$. (b). $T_{c, \max }=1273 \mathrm{~K}$.

semicharcoal (Japanese cypress) and semichar (Newcastle blend coal) carbonised at $T_{c, \text { max }}=823,1073$, and $1273 \mathrm{~K}$ and $r_{h}=200 \mathrm{~K} / \mathrm{h}$ at reduction temperature $T_{R}=1273 \mathrm{~K}$ in an $\mathrm{N}_{2}$ gas atmosphere. The reduction of carbon composite pellets using semicharcoal (Japanese cypress) proceeded faster than that using semichar (Newcastle blend coal).

Figure 22 shows weight loss curves of semichar from Newcastle blend coal obtained by carbonisation at $T_{c, \text { max }}=823,1073$, and $1173 \mathrm{~K}$ and a coke sample (Table 6) at a gasification temperature $T_{G}=1273 \mathrm{~K}$ in $\mathrm{CO}_{2}$ gas atmosphere. The experimental apparatus for measuring the

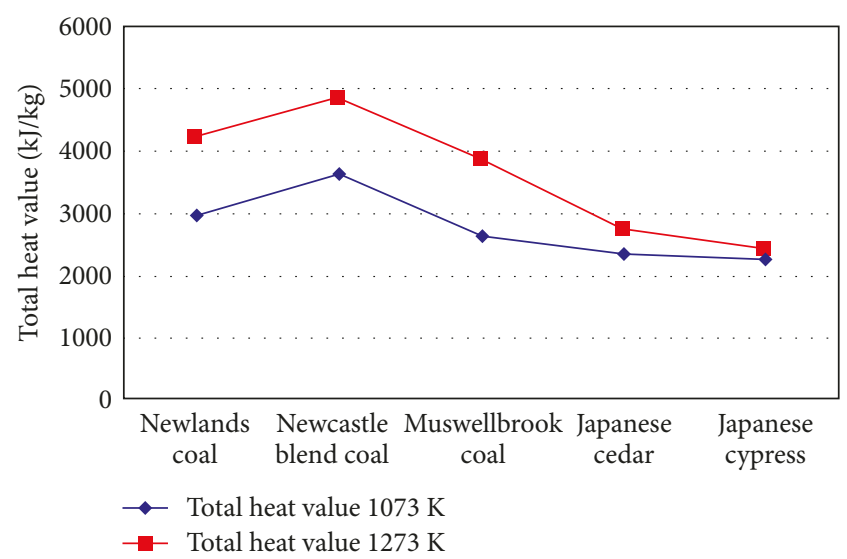

FIgURE 18: Total amount of heat $(\mathrm{kJ} / \mathrm{kg})$ of each sample at the maximum carbonisation temperature $T_{c, \max }=1073$ and $1273 \mathrm{~K}$ $\left(r_{h}=200 \mathrm{~K} / \mathrm{h}\right)$.

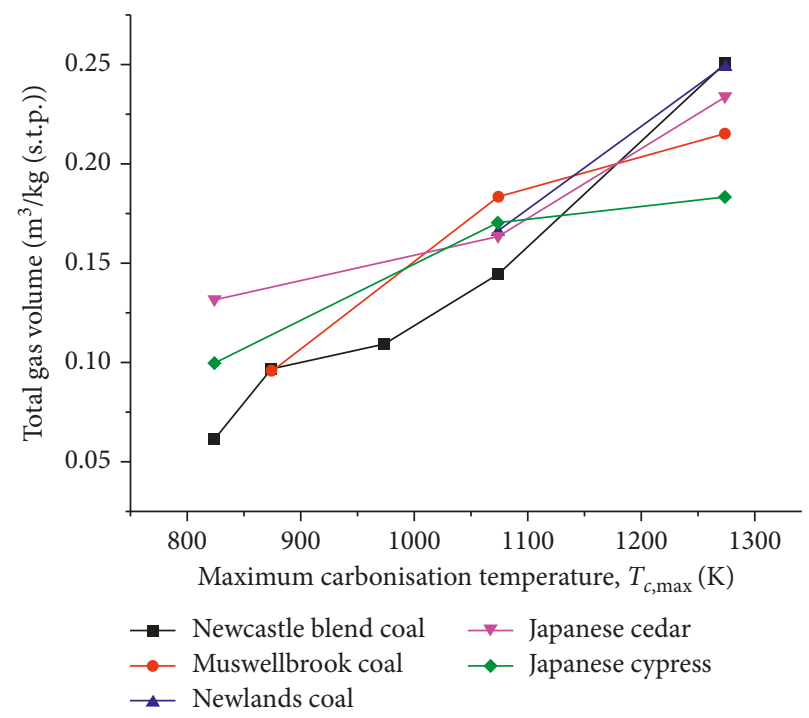

FIgURE 19: Total carbonisation gas volumes for all the samples used as a function of the maximum carbonisation temperature $\left(r_{h}=200 \mathrm{~K} / \mathrm{h}\right)$.

weight loss due to gasification of carbonaceous materials by a gravimetric method is the same as shown in Figure 20. Figure 23 shows weight loss curves of semicharcoal made from Japanese cypress obtained by carbonisation at $T_{c, \max }=823,1073$, and $1273 \mathrm{~K}$ and a coke sample at $T_{G}=1273 \mathrm{~K}$ in $\mathrm{CO}_{2}$ gas atmosphere. From comparison of these figures, it can be concluded that the gasification rate of semicharcoal is higher than that of semichar.

In Figure 14, XRD measurements are shown; Semicharcoal has an amorphous nature, while semichar has a more crystalline structure. As shown in Figure 16, semicharcoal is very porous. From these facts, semicharcoal can be expected to be very reactive.

Figure 24 shows Arrhenius plots of the reaction rate of gasification for semichar and semicharcoal produced at $T_{c, \text { max }}=1073 \mathrm{~K}$ as well as for coke, which are the 


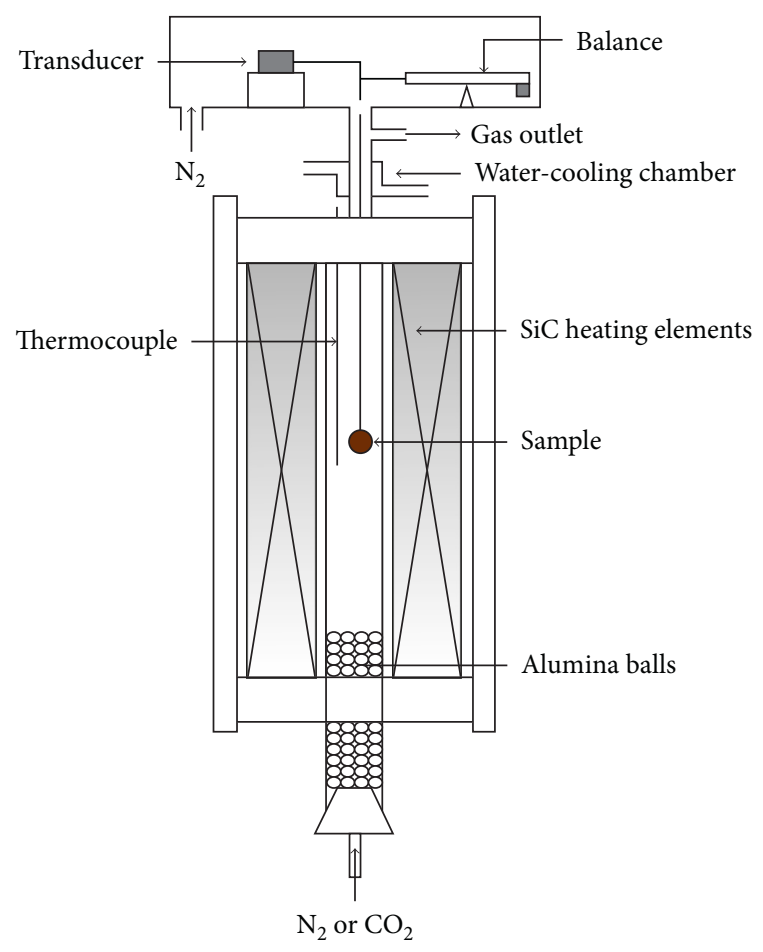

FIgURE 20: Experimental apparatus for measuring weight loss of a sample by the gravimetric method.

same as in Figures 22 and 23. The reaction rate $r(1 / \mathrm{s})$ is given by

$$
r=\frac{d X}{d t}
$$

where $t=$ reaction time (s) and $X=\left(W_{0}-W_{t}\right) / W_{0}$, in which $W_{0}$ is the initial mass $(\mathrm{g})$ and $W_{t}$ is the mass at reaction time $t(\mathrm{~g})$. The gradient for semicharcoal is the smallest, and hence, its activation energy is the lowest. Table 5 shows comparison of activation energies for various carbonaceous materials from Kawakami et al. [16] and the data derived from this study. The most active one (the lowest activation energy) in this table is "semicharcoal at $T_{c, \max }=823 \mathrm{~K}$." The activation energy for "semicharcoal at $T_{c, \max }=1073 \mathrm{~K}$ " is lower than that for "semichar at $T_{c, \max }=1073 \mathrm{~K}$," which means that semicharcoal is more reactive than semichar.

4.4. Heat Value of Carbonisation Gas. In order to evaluate the thermal potential of the gas components, the amount of heat $(\mathrm{kJ} / \mathrm{kg})$ has been calculated as for Newcastle blend coal in Table 7. As $T_{c, \text { max }}$ increases, the amounts of heat of $\mathrm{H}_{2}$ and $\mathrm{CO}$ also increase. The amounts of heat of $\mathrm{CH}_{4}$ within the temperature range of $T_{c, \max }=823$ to $973 \mathrm{~K}$ are much the same within some experimental error, but those from $T_{c, \text { max }}=973$ to $1273 \mathrm{~K}$ increase monotonically. With regard to higher hydrocarbons, almost all these carbonisation gases $\left(\mathrm{C}_{2} \mathrm{H}_{4}, \mathrm{C}_{2} \mathrm{H}_{6}\right.$, and $\left.\mathrm{C}_{3} \mathrm{H}_{8}\right)$ are evolved before the carbonisation temperature reaches at a little above $823 \mathrm{~K}$, and therefore, the amounts of heat values for

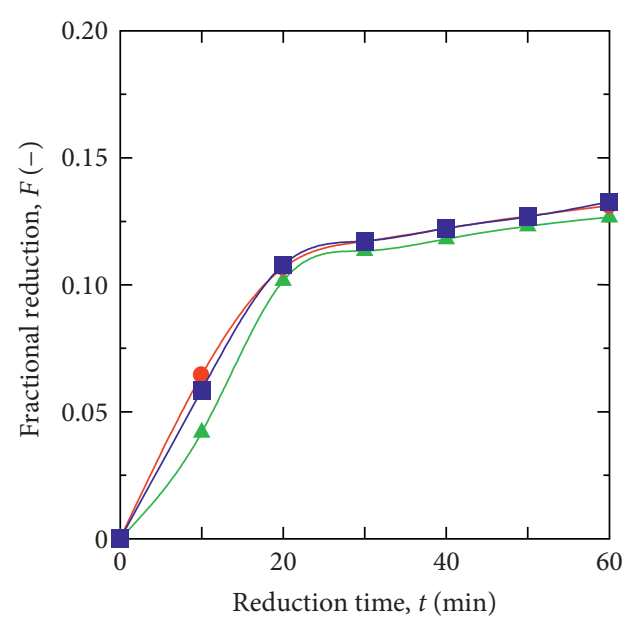

The particle size ranges:

$$
\begin{aligned}
& \text { - } 23-35 \mu \mathrm{m} \\
& \quad 63-75 \mu \mathrm{m} \\
& \text { - } 105-150 \mu \mathrm{m}
\end{aligned}
$$

(a)

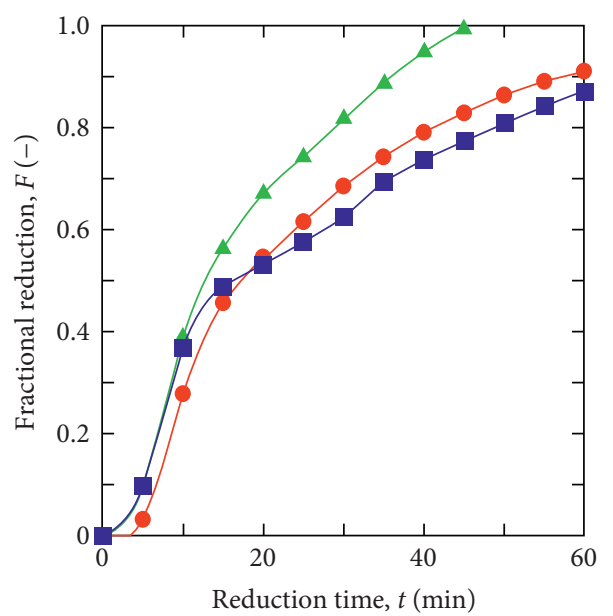

The particle size ranges:

- 23-35 $\mu \mathrm{m}$

- $63-75 \mu \mathrm{m}$

- 105-150 $\mu \mathrm{m}$

(b)

FIGURE 21: Influence of particle size of semicharcoal upon the reduction curves at the reduction temperature $T_{R}=1073$ and $1273 \mathrm{~K}$ in $\mathrm{N}_{2}$ gas atmosphere for carbon composite iron oxide pellets using semicharcoal produced at $T_{c, \text { max }}=1073 \mathrm{~K}$ and $r_{h}=200 \mathrm{~K} / \mathrm{h}$ from Japanese cypress. (a) $T_{R}=1073 \mathrm{~K}$. (b) $T_{R}=1273 \mathrm{~K}$.

$\mathrm{C}_{2} \mathrm{H}_{4}+\mathrm{C}_{2} \mathrm{H}_{6}+\mathrm{C}_{3} \mathrm{H}_{8}$ have no dependence upon the maximum carbonisation temperature $T_{c, \text { max }}$ over the $T_{c, \max }$ range from 823 to $1273 \mathrm{~K}$ but are scattered randomly. These tendencies can be easily understood by observing each gas emission behaviour at each $T_{c, \max }$ for Newcastle blend coal (see Figures 3 to 7 in [10]; Figure 7 in [10] is shown in this paper as Figure 10) or mole fraction variation for Muswellbrook coal (Figure 4). As a whole, the 


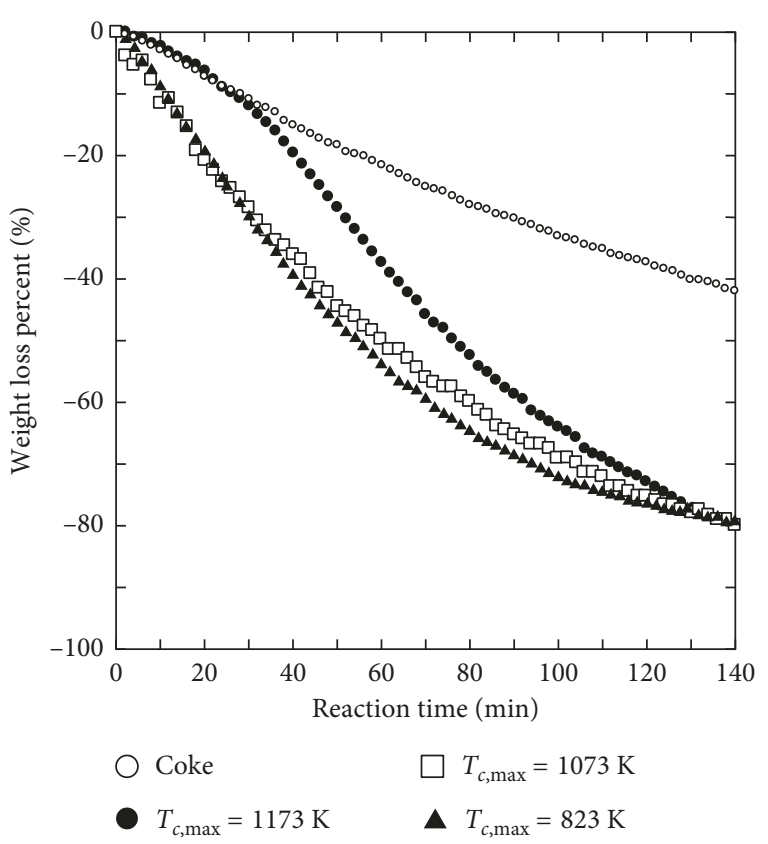

Figure 22: Weight loss curves of semichar samples (Newcastle blend coal) obtained by carbonisation at $T_{c, \max }=823,1073$, and $1173 \mathrm{~K}$ and a coke sample (Table 6) at a gasification temperature $T_{G}=1273 \mathrm{~K}$ in $\mathrm{CO}_{2}$ gas atmosphere.

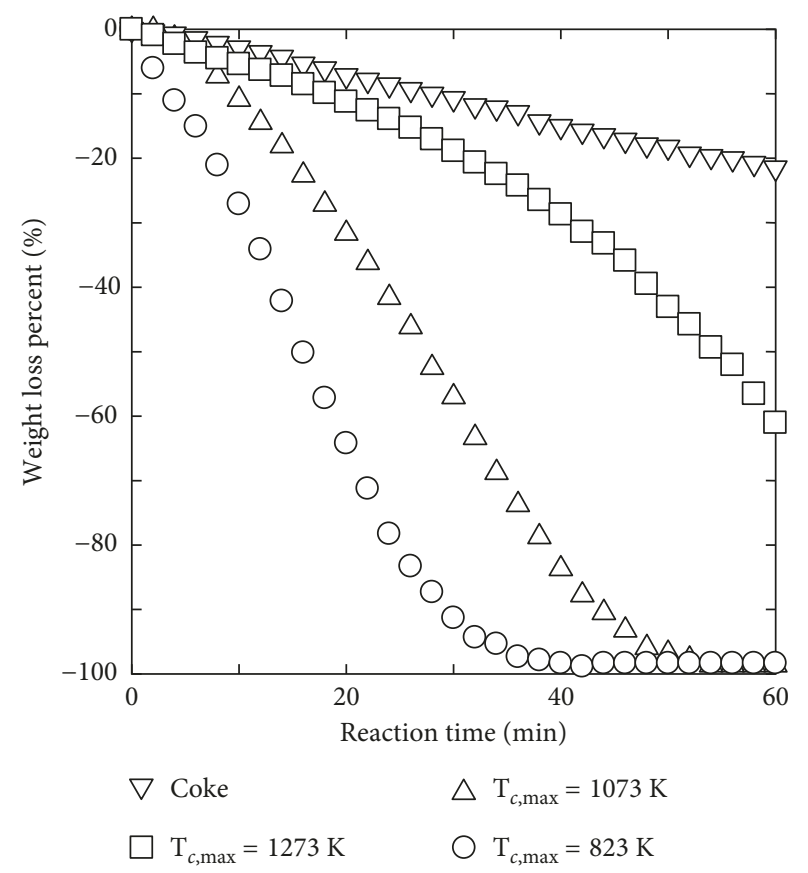

Figure 23: Weight loss curves of semicharcoal samples (Japanese cypress) obtained by carbonisation at $T_{c, \max }=823,1073$, and $1273 \mathrm{~K}$ and a coke sample (Table 6) at $T_{G}=1273 \mathrm{~K}$ in $\mathrm{CO}_{2}$ gas atmosphere.

total heat values tend to increase almost monotonically, as $T_{c, \text { max }}$ increases.

Figure 18 shows the comparison among the total amounts of heat for all the samples used at $T_{c, \max }=1073$ and $1273 \mathrm{~K}$. Amounts of heat for coal are somewhat higher

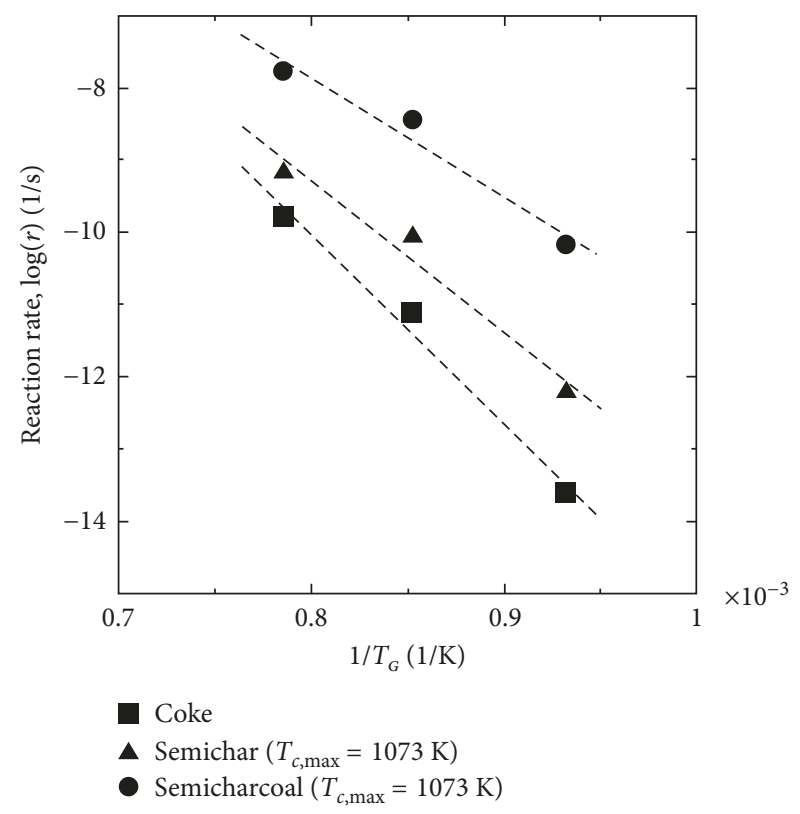

Figure 24: Arrhenius plots of the reaction rate of gasification for semichar and semicharcoal produced at $T_{c, \max }=1073 \mathrm{~K}$ as well as for coke, which are the same as in Figures 22 and 23. The reaction rate $r(1 / \mathrm{s})$ is defined by $(2)$ and $T_{G}$ : gasification temperature $(\mathrm{K})$.

TABLe 7: Amount of heat $(\mathrm{kJ} / \mathrm{kg})$ of each gas component as a function of maximum carbonisation temperature $T_{c, \text { max }}$ (Newcastle blend coal, $r_{h}=200 \mathrm{~K} / \mathrm{h}$ ).

\begin{tabular}{lccccc}
\hline$T_{c, \text { max }}(\mathrm{K})$ & 823 & 873 & 973 & 1073 & 1273 \\
\hline $\mathrm{H}_{2}$ & 24 & 453 & 555 & 1010 & 1648 \\
$\mathrm{CO}$ & 64 & 109 & 163 & 267 & 254 \\
$\mathrm{CH}_{4}$ & 1384 & 1079 & 1145 & 1842 & 2206 \\
$\mathrm{C}_{2} \mathrm{H}_{4}+\mathrm{C}_{2} \mathrm{H}_{6}+\mathrm{C}_{3} \mathrm{H}_{8}$ & 688 & 725 & 320 & 509 & 725 \\
Total & 2160 & 2366 & 2183 & 3628 & 4833 \\
\hline
\end{tabular}

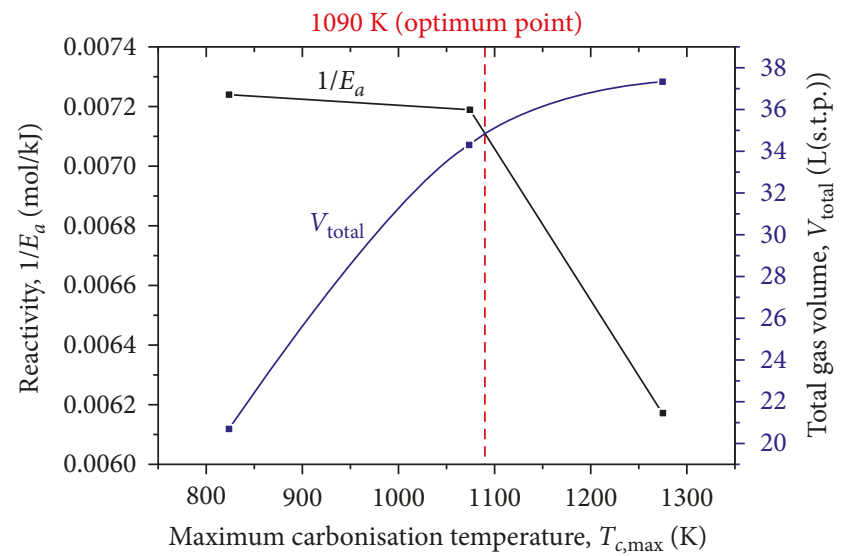

FIgURE 25: Reactivity of semicharcoal and total carbonisation gas volume as a function of the maximum carbonisation temperature $T_{c \text {, max }}\left(r_{h}=200 \mathrm{~K} / \mathrm{h}\right)$ for Japanese cypress (sample weight in wood stage: $200 \mathrm{~g}$ ). 
than those for wood. The total amount of heat at $T_{c \text {,max }}=$ $1273 \mathrm{~K}$ is always higher than the one at $T_{c, \max }=1073 \mathrm{~K}$ for all the samples used.

4.5. Reactivity of Semicharcoal and the Total Carbonisation Gas Volume. Figure 25 shows the reactivity of semicharcoal and the total carbonisation gas volume for Japanese cypress as a function of the maximum carbonisation temperature $T_{c \text {, max }}$. The reactivity was calculated by the reciprocal of the activation energy $E_{a}(\mathrm{~kJ} / \mathrm{mol})$ (Table 5). Because the scales of both ordinates are arbitrary, the optimum point cannot be considered absolute. However, we can envisage that there will be an optimum point for both high reactivity of semicharcoal and large volume of the emitted carbonisation gas, or biogas. Such an optimum point should be determined in consideration of the usage of the semicharcoal and carbonisation gas.

\section{Conclusions}

Carbon composite iron oxide pellets using semichar or semicharcoal were proposed from the measured results of the coal carbonisation gas release behaviour for prereduction of iron oxide, which was a part of the fundamental study for smelting reduction total process. The samples used were Newlands coal, Newcastle blend coal, Muswellbrook coal, Japanese cedar, and Japanese cypress to prepare semichar and semicharcoal as carbonaceous materials, and coke was also used for reference. The carbonisation was completed under rising temperature conditions at a constant heating rate (mainly at $200 \mathrm{~K} / \mathrm{h}$ ) until arriving at the maximum carbonisation temperature $T_{c, \max }$ in order to release some volatile matter (VM). Conclusions obtained are as follows:

(1) Comparison of reduction curves for carbon composite pellets using semichar produced at $T_{c, \max }=$ $823 \mathrm{~K}$ and coke and graphite at the reduction temperature $T_{R}=1273 \mathrm{~K}$ showed that the reduction rate of the semichar composite pellet was the highest and that of graphite was the lowest.

(2) From [14], the rate of reduction for semicharcoal composite pellets was greater than that for semichar composite pellets because the gasification rate of semicharcoal is higher than that of semichar for the following reasons: the amorphous nature of semicharcoal is stronger than that of semichar, and the activation energy of semicharcoal is lower than that of semichar.

(3) The starting point of reduction of the carbon composite pellet using semicharcoal produced at $T_{c, \text { max }}=823 \mathrm{~K}$ in $\mathrm{N}_{2}$ gas atmosphere was observed to be at the reduction temperature $T_{R}=833 \mathrm{~K}$, only a little higher than $T_{c \text {, max }}$, which was the target of the experiment.

(4) For all the samples, the total carbonisation gas volume increases, as the maximum carbonisation temperature $T_{c, \max }$ increases. The heat value of the carbonisation gas depends on $T_{c, \max }$ and consequently the emitted gas volume and the composition. As a whole, the total heat value tends to increase almost monotonically, as $T_{c, \max }$ increases.

(5) Large quantities of $\mathrm{H}_{2}$ and $\mathrm{CH}_{4}$ are released from the sample coals. This can be explained from the structure of the coal, which is mainly composed of carbon and hydrogen. In contrast, large amounts of $\mathrm{CO}$ and $\mathrm{CO}_{2}$ are released from the sample woods because of the large quantity of oxygen in its structure.

(6) The effect of the particle size of the carbonaceous material on the reduction rate was studied by using semicharcoal composite pellets. When $T_{R}$ is higher than $T_{c \text {, } \max }$, the reduction rate increases, as the particle size decreases. When $T_{R}$ is equal to $T_{c \text {, max }}$, there is almost no effect.

(7) The maximum carbonisation temperature $T_{c \text {, max }}$ can be used to control the evolved and residual gas volumes. With decreasing $T_{c \text {, max }}$, the activation energy $E_{a}$ of semicharcoal decreases, or the reactivity $1 / E_{a}$ of semicharcoal increases. The maximum carbonisation temperature $T_{c, \max }$ may be optimised for reactivity of semicharcoal and the total carbonisation gas volume or the heat value.

\section{Conflicts of Interest}

All authors declare that there are no conflicts of interest regarding the publication of this paper.

\section{Acknowledgments}

The authors wish to express their thanks to Mr. Kazuhiro Azuma (Bachelor of Engineering), Mr. Takeshi Harada (Master of Engineering), Mr. Atsushi Yamashita (Master of Engineering), and Mr. Shiro Fujimori (Bachelor of Engineering), graduated students of Osaka University, at the time of study, for their help. The authors would like to express their gratitude to FAPEMIG, Brazil, for their financial support.

\section{References}

[1] T. Ariyama and M. Sato, "Optimization of ironmaking process for reducing $\mathrm{CO}_{2}$ emissions in the integrated steel works," ISIJ International, vol. 46, no. 12, pp. 1736-1744, 2006.

[2] M. Asanuma, T. Ariyama, M. Sato et al., "Development of waste plastics injection process in blast furnace," ISIJ International, vol. 40, no. 3, pp. 244-251, 2000.

[3] T. Ariyama, R. Murai, J. Ishii, and M. Sato, "Reduction of $\mathrm{CO}_{2}$ emissions from integrated steel works and its subject for a future study," ISIJ International, vol. 45, no. 10, pp. 13711378, 2005.

[4] T. Matsumura, M. Ichida, T. Nagasaka, and K. Kato, "Carbonization behaviour of woody biomass and resulting metallurgical coke," ISIJ International, vol. 48, no. 5, pp. 572-577, 2008.

[5] M. Nakano, M. Naito, K. Higuchi, and K. Morimoto, "Nonspherical carbon composite agglomerates: lab-scale manufacture and quality assessment," ISIJ International, vol. 44, no. 12, pp. 2079-2085, 2004. 
[6] T. Usui, T. Yokoyama, T. Nakahashi, and Z. Morita, "Effective use of hydrogen within coal in pre-reduction of iron oxide for minimizing the amounts of coal used and $\mathrm{CO}_{2}$ exhausted in an iron bath smelting reduction process," in Proceedings of Ironmaking Conference, vol. 52, pp. 389-398, The Iron and Steel Society of AIME, Dallas, Texas, USA, March 1993.

[7] T. Usui, N. Inoue, T. Watanabe, T. Yokoyama, T. Oyama, and Z. Morita, "Influence of reduction temperature on prereduction of iron oxide with coal carbonisation gas without tar," Ironmaking and Steelmaking, vol. 31, no. 6, pp. 479-484, 2004.

[8] N. Inoue and T. Usui, "Influence of combined water in coal on pre-reduction of iron oxide with coal carbonization gas in low, middle and high volatile matter coal," Journal of High Temperature Society, vol. 35, no. 1, pp. 26-32, 2009.

[9] T. Usui, T. Yokoyama, T. Ohyama, T. Nakahashi, M. Nonaka, and Z. Morita, "Effective use of volatile matter in pre-eduction of iron oxide for minimizing the amounts of coal used in an in-bath smelting reduction process," in Proceedings of the Second International Symposium on Metallurgical Processes for the Year 2000 and Beyond and the 1994 TMS Extraction and Process Metallurgy Meeting, Vol. I, pp. 693-714, TMS (The Minerals, Metals and Materials Society), San Diego, CA, USA, September 1994.

[10] H. Konishi, T. Usui, and K. Azuma, "The preparation and reduction behavior of carbon composite iron oxide pellets using semi-coal-char," Tetsu-to-Hagané, vol. 92, no. 12, pp. 802-808, 2006.

[11] H. Konishi, A. Yamashita, and T. Usui, "Effect of residual volatile matter on reduction of iron oxide in carbon composite pellets," Journal of JSEM (Japanese Society for Experimental Mechanics), vol. 8, Special Issue, pp. 142-146, 2008.

[12] H. Konishi, T. Usui, and A. Yamashita, "Effect of residual volatile matter on reduction reaction between semi-coal-char and iron oxide," Tetsu-to-Hagané, vol. 95, no. 6, pp. 467-472, 2009.

[13] H. Konishi, K. Ichikawa, and T. Usui, "Effect of residual volatile matter on reduction of iron oxide in semi-charcoal composite pellets," ISIJ International, vol. 50, no. 3, pp. 386-389, 2010.

[14] H. Konishi, T. Usui, and T. Harada, "The preparation and reduction behavior of charcoal composite iron oxide pellets," Journal of High Temperature Society, vol. 34, no. 1, pp. 14-19, 2008.

[15] H. Konishi, S. Fujimori, and T. Usui, "Reduction behavior of iron oxide in semi-charcoal composite pellets," Journal of High Temperature Society, vol. 35, no. 1, pp. 33-39, 2009.

[16] M. Kawakami, H. Taga, T. Takenaka, and S. Yokoyama, "Micro pore structure and reaction rate of coke, wood charcoal and graphite with $\mathrm{CO}_{2}$," ISIJ International, vol. 44, no. 12, pp. 2018-2022, 2004. 


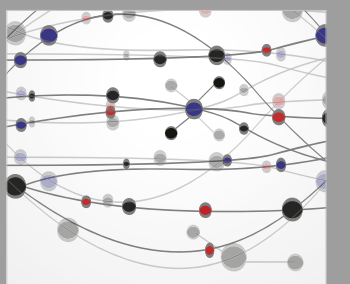

The Scientific World Journal
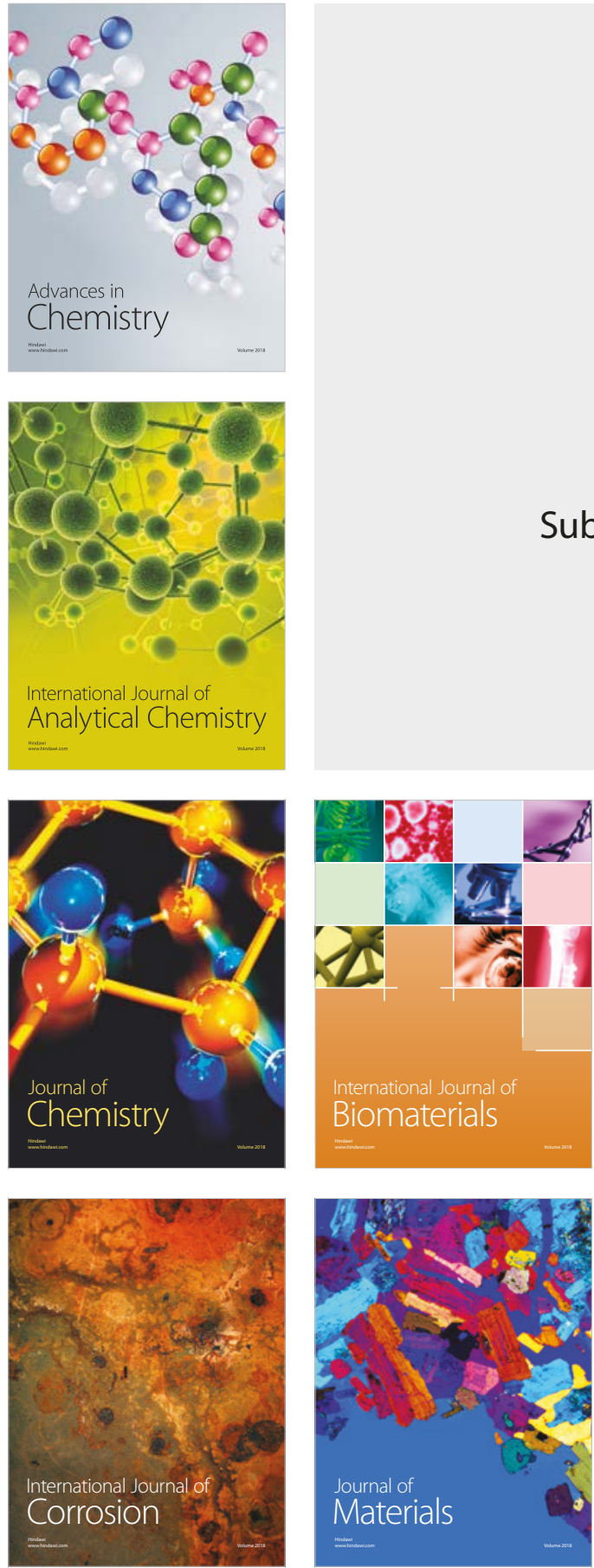

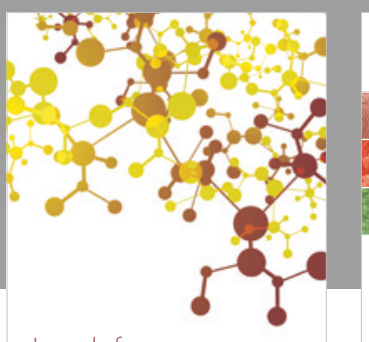

Journal of

Applied Chemistry
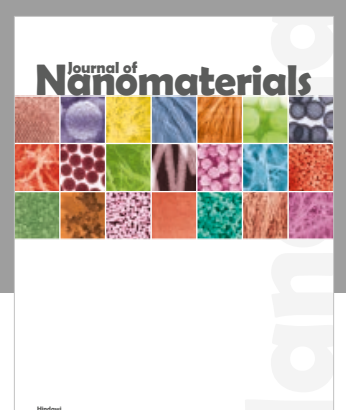

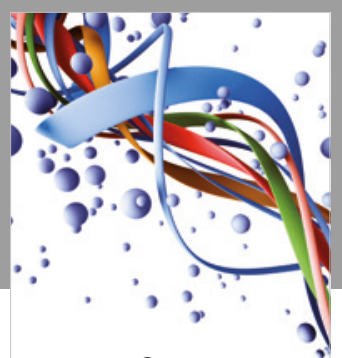

Scientifica

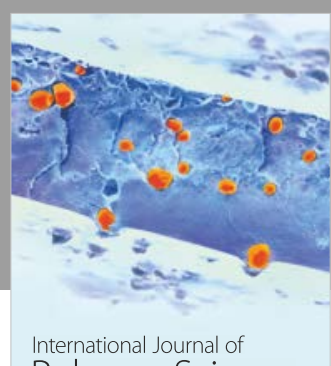

Polymer Science

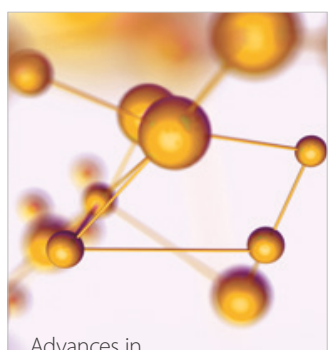

Physical Chemistry
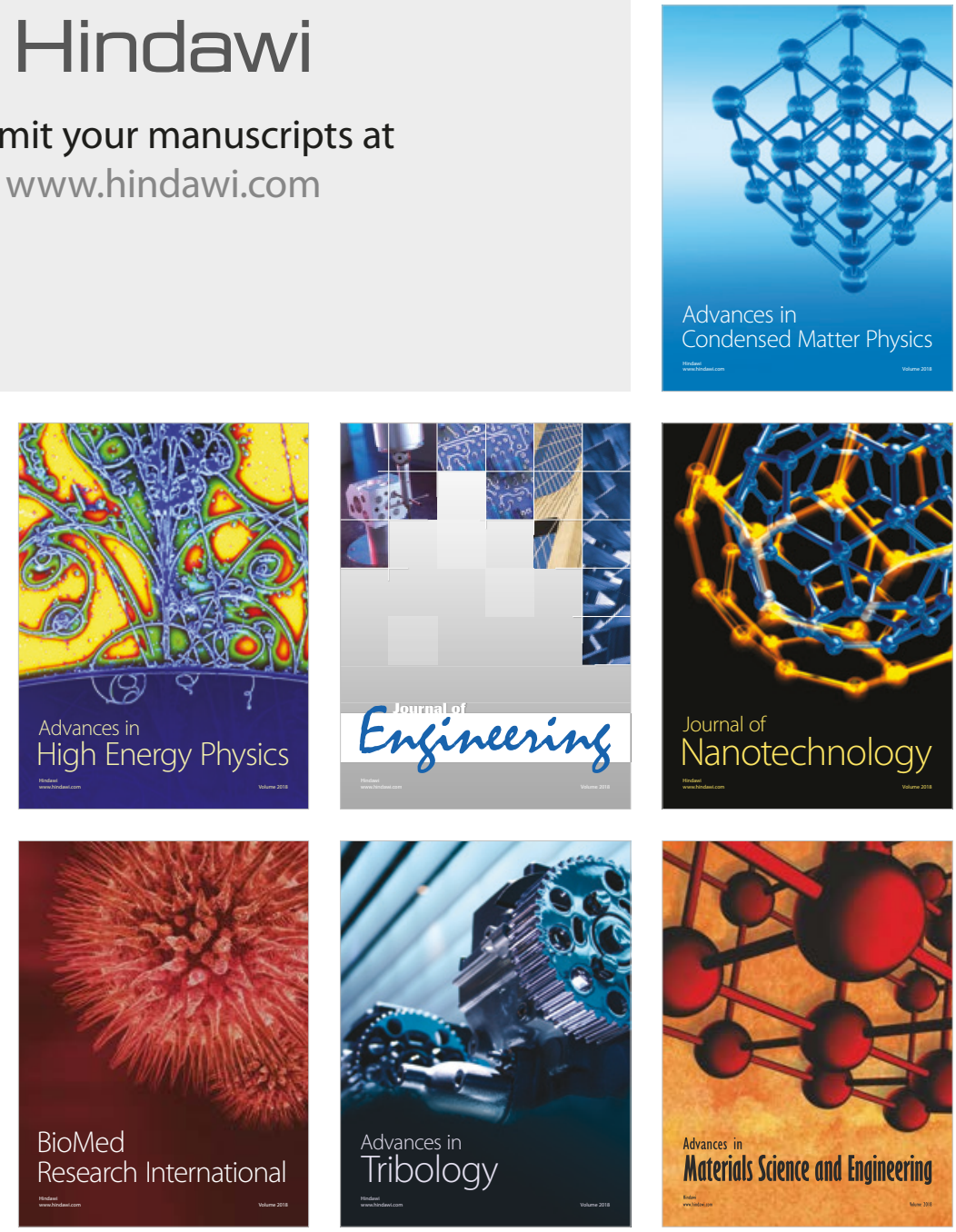